\title{
A Potential Mitigation Measure of the Seismic Distress of the Circuit Wall at the Acropolis of Athens
}

\section{Manolis Katsirakis}

Technical University of Crete, School of Environmental Engineering

Yiannis Tsompanakis ( $\boldsymbol{\nabla}$ jt@science.tuc.gr)

Technical University of Crete School of Environmental Engineering https://orcid.org/0000-0002-89990500

\section{Prodromos N. Psarropoulos}

National Technical University of Athens School of Rural and Surveying Engineering

\section{Research Article}

Keywords: Retaining walls, dynamic earth pressures, mitigation measures, Acropolis Circuit Wall, expanded polystyrene, numerical simulations

Posted Date: May 11th, 2021

DOI: https://doi.org/10.21203/rs.3.rs-486935/v1

License: (c) (i) This work is licensed under a Creative Commons Attribution 4.0 International License. Read Full License 


\title{
A potential mitigation measure of the seismic distress of the Circuit Wall at the Acropolis of Athens
}

\author{
Manolis Katsirakis ${ }^{1}$, Yiannis Tsompanakis ${ }^{2 *}$, \\ Prodromos N. Psarropoulos ${ }^{3}$ \\ ${ }^{I}$ School of Environmental Engineering, Technical University of Crete, Chania, Greece \\ katsiman@hotmail.com \\ ${ }^{2}$ School of Environmental Engineering, Technical University of Crete, Chania, Greece \\ jt@science.tuc.gr \\ ${ }^{3}$ School of Rural and Surveying Engineering, National Technical University of Athens, Greece \\ prod@central.ntua.gr
}

*Corresponding author: Professor Yiannis Tsompanakis Address: Sciences Building - Office 141.B.86, University Campus, School of Environmental Engineering, Technical University of Crete, Chania, 73100, Crete, Greece Tel: +30 2821037634 \& E-mail: jt@,science.tuc.gr ORCID: 0000-0002-8999-0500

\begin{abstract}
The seismic design of new retaining structures is usually performed following modern seismic norms. Nonetheless, there are various monumental retaining structures (e.g., fortifications) with high seismic vulnerability, which must be protected against earthquakes, while there are several limitations on the type of mitigation measures that can be applied to such cultural heritage structures. The present study investigates numerically the seismic response and distress of the Circuit Wall of the Athenian Acropolis. The Wall is a monumental masonry retaining structure surrounding the world-class monuments of the archeological hill of the Acropolis. Given the fact that the wider region of Athens is characterized by moderate to high seismicity, it is necessary to protect the Wall from strong ground motions. For this purpose, the geological, seismological, and topographic conditions of the Acropolis hill, as well as the geometry and the mechanical properties of the Wall, are realistically taken into account. A representative finite-element model has been developed for a critical section of the Wall, which has been validated with available records from accelerometers being installed at the Wall. Subsequently, an efficient and suitable -according to international monument restoration guidelines- seismic mitigation measure is proposed. The results of dynamic earth-pressure distribution on the Wall are presented before and after the application of expanded polystyrene (EPS) blocks behind the Wall. A detailed parametric study illustrates a substantial reduction of dynamic pressures on the Wall when the EPS blocks are applied, either along the entire height or only at the lower part of the Wall.
\end{abstract}

Keywords: Retaining walls; dynamic earth pressures; mitigation measures; Acropolis Circuit Wall; expanded polystyrene; numerical simulations. 


\section{Introduction}

Retaining systems are used in many engineering projects in order to support one or more soil layers and in some cases, various structures founded on the soil layer(s). Bridge abutments, basement walls, harbor quay walls or most simple forms, such as a typical gravity wall, comprise the most frequent applications of retaining structures. Generally, the seismic response of even a simple retaining wall is a very complex problem of soil-structure interaction (Kramer 1996). The backfill material can impose high earth pressures on the wall both under static and dynamic (i.e., seismic) conditions. This fact may lead to local or global structural failures with severe economic losses. According to Psarropoulos et al. (2005), the magnitude of the earth pressures depends, not only on the mechanical and geometrical properties of the wall and the retained soil, but on the various "degrees of freedom" of the system (i.e., structural flexibility, base compliance, sliding, etc.) as well, while the characteristics of the seismic motion have also a significant impact.

Many researchers have examined the response of a retaining wall under seismic conditions with analytical, numerical, and/or experimental studies. Regarding analytical methods, there are two main categories to estimate the dynamic (i.e., seismic) earth pressures acting on the wall due to the backfill material: (a) the limit-equilibrium methods and (b) the elasticity-based methods. The limit-equilibrium methods are usually pseudo-static approaches that consider yielding walls and plastic behavior of the backfill material (Mononobe and Matsuo 1929; Seed and Whitman 1970). In contrast, the elasticity-based methods consider that the backfill material has a viscoelastic behavior (Wood 1973). In addition, a viscoelastic behavior of the backfill material and an elastic behavior of the wall has been assumed in several numerical studies (e.g., Psarropoulos et al. 2005).

Nowadays, the design of a retaining structure is based on modern seismic norms and guidelines, such as Eurocode 8 (EC8, 2004). In these norms, the soil-structure interaction is considered in a simplified manner and the calculation of the seismic pressures is mainly achieved via the Mononobe-Okabe method (Okabe 1926, Mononobe \& Matsuo 1929), which is actually a pseudo-static extension of Coulomb's static method. Nevertheless, the walls are designed to withstand the earth pressures from the backfill material under static and seismic conditions. Hence, few damages have been reported for recently designed walls subjected to seismic earth pressures. In addition, various seismic mitigation measures can be applied during the wall construction to enhance its dynamic performance. In contrast, old retaining walls have not been designed using any seismic norms, a fact that certainly increases their vulnerability against dynamic loading. Therefore, many local or global damages may appear during a severe seismic event. In such cases, the application of seismic mitigation measures is more pronounced to protect the retaining wall.

The protection of cultural heritage is an important issue from every aspect and extremely challenging from an engineering perspective. A detailed set of guidelines has been developed for the restoration and conservation of all types of monuments, known as Charter of Venice, was established in 1964. Many existing retaining walls have been characterized as monuments (e.g., old fortification walls with backfill materials). These ancient retaining walls are made of stone and have suffered various damages (e.g., corrosion, cracks and local failures) over the years due to human interventions and/or natural hazards. A strong ground motion could affect 
the structural integrity of these retaining walls, due to the increased dynamic earth pressures that may lead to local or global failures (Egglezos et al. 2013). The application of seismic mitigation measures on ancient retaining walls is a very difficult and challenging task for engineers, due to their monumental character and the related restrictions. Therefore, the number of such interventions on ancient retaining walls worldwide is rather limited.

The current study investigates the seismic response of a characteristic section at the southern Acropolis Circuit Wall via two-dimensional dynamic analyses utilizing the finite-element method. A thorough investigation has been performed with respect to the potential reduction of the dynamic pressures imposed on the Wall, which can be achieved via the inclusion of expanded polystyrene blocks (EPS) behind the monumental structure. This seismic mitigation measure has been efficiently used in modern retaining walls and its application for protecting monumental retaining systems is proposed for the first time in this work. Moreover, EPS can be characterized as a mild intervention scheme, which is compatible with the regulations for monumental structures, and can provide adequate seismic protection to the Wall. The proposed EPS application does not alter the monumental character of the Wall both visually and architecturally, as it can be covered by the excavation backfill material. A detailed parametric analysis regarding the type, the height and the thickness of EPS behind the Wall has been conducted. Despite the various uncertainties related to the numerical simulation of this complex problem, the results are very promising since they reveal a substantial beneficial impact of EPS on the reduction of seismic distress of the Wall.

\section{Seismic distress of retaining walls and mitigation with EPS}

\subsection{Dynamic analysis methods of retaining walls}

As aforementioned, various analytical and numerical methods have been developed to determine the seismic earth pressures and the dynamic distress of a retaining wall. Although a detailed review is beyond the scope of the current study, a brief description of several characteristic studies is provided in this section. Mononobe \& Matsuo (1929) and Okabe (1926) developed a pseudo-static analytical approach to calculate the seismic earth force acting on the wall. According to this method, pseudo-static inertial forces act in both horizontal and vertical directions on the retained soil wedge. The proposed simplified mathematical formulas can be applied to calculate the active and passive seismic pressures on a wall. For typical values of internal angle of friction of the soil, the simplified method of Seed and Whitman (1970) can alternatively be used.

Wood (1973) investigated the seismic response of an isotropic homogeneous elastic soil within two rigid walls, located on the top of a rigid base. This study revealed that when the two rigid systems have an adequate distance (i.e., approximately five times the height of the wall), the dynamic earth pressures acting on both walls do not exhibit any interaction. In addition, for seismic excitations with low frequency and especially for frequencies lower than the half of the fundamental frequency of the soil layer for horizontal conditions $\left(f_{0}=V_{S} / 4 H\right)$, the seismic pressures acting on the wall can be calculated considering that the system (wall and backfill material) exhibits elastic behavior. 
Veletsos and Younan $(1994,1997)$ estimated the magnitude and the distribution of the seismic earth pressures on the wall imposed by a horizontal seismic excitation using a simplified analytical methodology. They considered that the wall consists of a flexible beam with rotational flexibility at its base, while the soil was considered homogeneous and viscoelastic. In general, the flexibility of the wall and its rotational base affected the distribution of the seismic earth pressures, while an increase of the wall flexibility led to a decrease of the dynamic earth pressures.

Psarropoulos et al. (2005), utilizing the finite-element method, developed a numerical model in order to reproduce the results from the analytical method of Veletsos and Younan (1994, 1997). The retaining wall was simulated with beam elements, while a rotational spring was installed at its base to simulate the rotational flexibility. The finite-element software ABAQUS was used for the performance of dynamic analyses under harmonic excitations. The obtained numerical results were consistent with the corresponding analytical solutions. In addition, different cases of wall and base stiffness were examined in order to investigate their impact on the distribution of the dynamic earth pressures.

\subsection{Application of EPS in retaining walls}

Expanded polystrene (EPS) is a composite material frequently used in many geotechnical projects, such as road and railway embankments, pipelines, retaining systems, etc. Typically, large parts of the soil can be replaced by EPS blocks to reduce the vertical and/or horizontal static and dynamic loads. The main reasons for using EPS are the following: low weight and relatively high strength, ease of construction, relatively low cost and durability. Moreover, EPS can be produced in different shapes and types with varying mechanical properties, which serve better the needs of each engineering project. One of EPS geotechnical engineering applications is as a compressible inclusion between a retaining wall and the retained soil. Several researchers have investigated, numerically and/or experimentally, the response of EPS as a seismic mitigation measure, which decreases the dynamic earth pressures from the backfill materials.

Zarnani and Bathurst (2009) developed a finite-element model in which a compressive inclusion of EPS was installed between the wall and the soil in order to examine the impact of EPS on the reduction of the seismic pressures. A parametric study was conducted regarding the thickness of the compressive inclusion, the type of EPS, the wall height and the frequency content of the seismic excitation. The interaction between EPS and backfill was simulated via a special interface element with zero thickness and $20^{\circ}$ friction angle obtained from physical tests. The results of this study showed that the application of EPS between the wall and the soil backfill material led to a significant reduction of the dynamic pressures. In particular, the reduction was greater than $55 \%$ when the ratio of the thickness of EPS to the wall height was equal to 0.4 .

Athanasopoulos-Zekkos et al. (2012) developed two numerical models of a retaining yielding wall, utilizing the finite-element software PLAXIS 2D. A parametric study was performed for two retaining wall heights and different thicknesses and shapes of the EPS compressive inclusion and different seismic intensity levels. The study showed that the most efficient EPS shape was the inverted triangle. However, a -more easily constructed- rectangular shape can be used since the differences were negligible. Moreover, the results illustrated that 
the efficiency of EPS in reducing of the seismic pressures was increased for higher thickness of EPS and decreased for higher magnitude of the imposed seismic excitations. However, this occurred up to a certain EPS thickness, as a further increase did not improve its efficiency.

Dabiri and Notash (2020) investigated the efficiency of EPS on a retaining wall under static and seismic conditions. They examined different types of walls (yielding and non-yielding) with $6 \mathrm{~m}$ and $9 \mathrm{~m}$ height, while two types of EPS (EPS15 and EPS20) were used with normalized thickness to wall height equal to 0.1 and 0.2 . Two seismic records, one near-field and one far-field, were used for the dynamic analyses utilizing the finite-element method. The results showed the beneficial impact of EPS both for static and dynamic loading conditions.

In all aforementioned studies, EPS was modeled as a linear elastic material. Apart from the numerical studies, some experimental investigations have also been reported. Athanasopoulos et al. (2007) performed a centrifuge test of a small-scale model of a wall with and without an EPS compressive inclusion. The results revealed a reduction of the seismic pressures due to the EPS, while the density of the EPS affected its efficiency. More specifically, EPS with lower density exhibited a greater efficiency. Zarnani and Bathurst (2007) also performed an experimental study at a shaking table using a small-scale model of a rigid wall, which was also examined numerically. The results of this study also illustrated the reduction of the seismic pressures due to EPS.

\section{Description of the Circuit Wall of the Acropolis}

\subsection{The Acropolis hill}

Acropolis of Athens is one of the most impressive monumental complexes in the world, and it has been included in the World Heritage Sites List of UNESCO since 1986. On the hill of the Acropolis, which dominates the center of the modern city of Athens, great monuments are located. Apart from Parthenon, which is the most prestigious ancient structure, the hill includes several other monuments, such as Propylaia and Erechteion, with great historical and architectural importance. One of them is the perimetric Circuit Wall, which is depicted in Fig. 1. The Circuit Wall is a masonry structure retaining the backfill materials that are used to flatten the surface of the hill. The Hellenic Ministry of Culture and the Acropolis Restoration Service (YSMA) have great interest in maintaining the structural integrity of the Wall. For this purpose, optical fiber sensors and accelerographs have been installed for the multi-disciplinary real-time monitoring of this complex historical site, as described by Kapogianni et al. (2019).

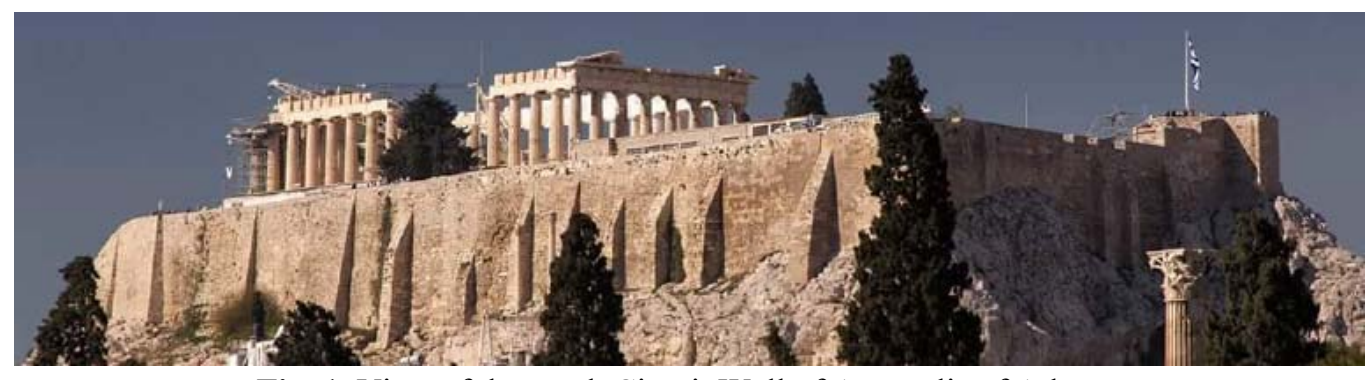

Fig. 1. View of the south Circuit Wall of Acropolis of Athens. 
The seismic response of any structure depends directly on the local site conditions, which can amplify and/or alter the frequency content of the seismic ground motion at the bedrock. Additionally, in the case of retaining systems, the properties and the typology of their foundation, the inclination of the bedrock, as well as the mechanical properties of the retained soil can also play a crucial role. As shown in Fig. 2, the Acropolis hill is composed of a limestone layer, which is located on top of the Athenian schist. The limestone is actually a hard rock, while schist is considered to be a soft rock (Psarropoulos et al. 2018). The thickness of the limestone does not exceed $40 \mathrm{~m}$. The slopes of the hill are almost vertical with a varying height up to $25 \mathrm{~m}$. On the other hand, the backfill material is thicker on the south side of the hill and it is retained by the Wall, while it is characterized as a soft soil material (Koukis et al. 2015). In addition, rockfall phenomena and additional erosion phenomena have occurred due to limestone karstification that has created cavities that facilitate the water flow (Higgins and Higgins 1996; Koukis et al. 2015).

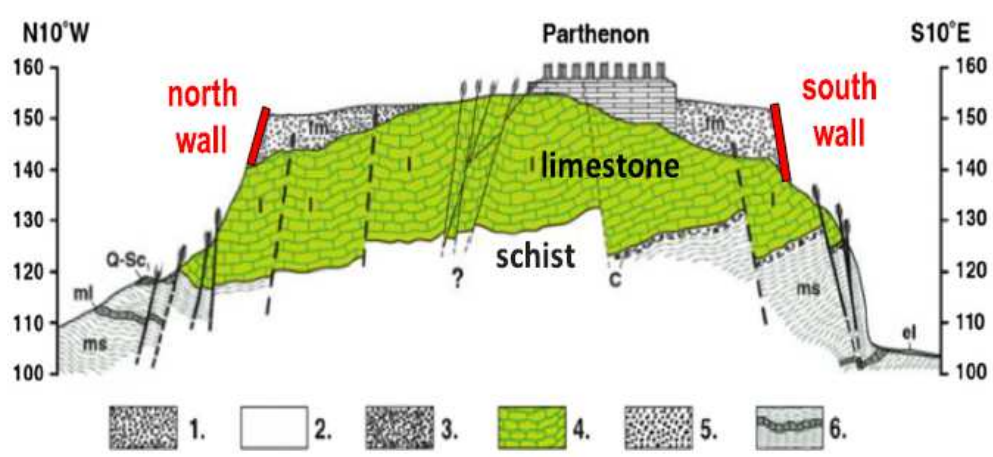

Fig. 2. The prevailing geological conditions on the hill of Acropolis: 1. Artificial earthfill. 2. Eluvial mantle. 3. Talus. 4. Limestone. 5. Conglomerates. 6. Schist- Sandstone - marl series (adopted from Koukis et al. 2015).

In general, the earthquake hazard for the ancient part of Athens around the Acropolis hill is relatively low (Ambraseys and Psycharis 2012). Thus, most probably, the structures on the hill have not been seriously damaged by a strong seismic event. Nonetheless, in recent history, the wider region of Athens has suffered from quite strong ground motions. Two of the most disastrous seismic events were the eastern Corinth gulf $(\mathrm{M}=6.6)$ earthquake in 1981, and especially the Parnitha $(M=5.9)$ earthquake in 1999 , from a fault rupture very close to Athens that caused many human losses. Some other seismic events that could have affected the monuments in recent history are the earthquakes of 1705 in Athens $(M=6.2), 1805$ in Athens $(\mathrm{M}<6)$ and 1837 in Troezen ( $M=5.5)$ (Psarropoulos et al. 2018).

In the context of the seismic activity monitoring on the hill, a network of accelerographs has been installed by the Institute of Geodynamics of the National Observatory of Athens (IGNOA) and the Acropolis Restoration Services (YSMA). The network includes ten accelerographs, which are mounted at different locations on the hill, while two of these accelerographs have been installed at the south Wall. More specifically, the first accelerograph is installed at the base of the Wall at the limestone, while the second is located at the backfill material at the top of the Wall (Kapogianni et al. 2019). 
The construction of the first fortification wall dates back to $1,200 \mathrm{BC}$ and it is called the 'Cyclopean' Wall. This Wall was built at the top of the hill until $480 \mathrm{BC}$, when it suffered extensive damages during the Persian wars. Then, the north side of the Wall was built again by Themistocles (Themistoclean Wall) and the south side by Kimon (Kimonion Wall). The total length of the Wall is approximately $800 \mathrm{~m}$, and its height varies between $5 \mathrm{~m}$ and $20 \mathrm{~m}$, having a width ranging from $1 \mathrm{~m}$ and $6 \mathrm{~m}$, depending on the local topography (Egglezos et al. 2013). The Wall, which is based on the inclined limestone bedrock (Eleftheriou 2015), is characterized by various construction and intervention phases. Its main construction materials are stones and marble blocks, while mortar and exterior coatings have also been used.

In the past, the Wall has been damaged during wars and also due to natural hazards. For this reason, many modifications and restorations have been performed. As shown in Fig. 3, static and dynamic pressures from the backfill materials have caused cracks on the Wall (Egglezos et al. 2013). Hence, the protection of the Wall against static and dynamic loads is a very important issue, since its failure would cause structural damages to the other monuments and buildings on the top of Acropolis hill.

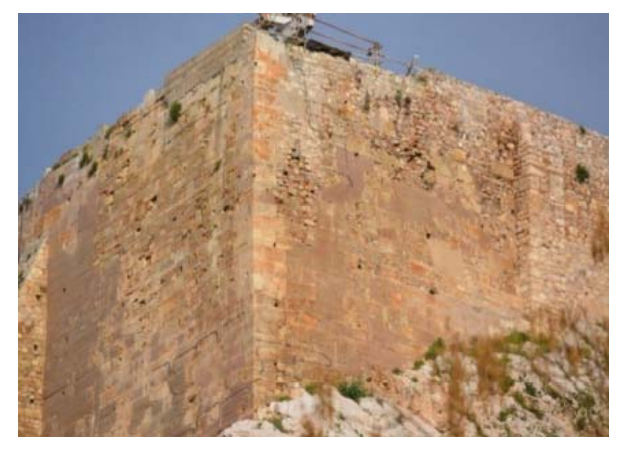

(a)

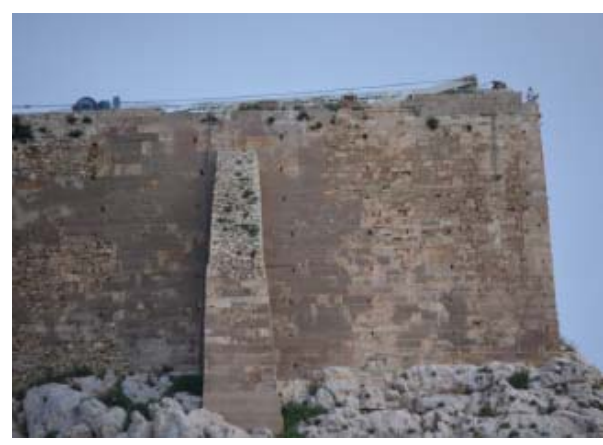

(b)

Fig. 3. Cracks at the southeast corner of the Wall: (a) view from the east, (b) view from the south.

\subsection{Numerical model of the Circuit Wall}

In this study, the seismic response of a specific Wall section, presented in Fig. 4(a), has been investigated via two-dimensional dynamic analyses. The selection of the specific location has been based on the following criteria:

a) The Wall height at this section is approximately $18 \mathrm{~m}$, which leads to increased earth pressures under both static and seismic conditions.

b) Some local failures (i.e., wide cracks) have been observed at this specific location (see Figs. $3(\mathrm{a})$ and (b)).

c) Two of the accelerographs of the Institute of Geodynamics have been installed at the base (ACRJ) and the top (ACRD) of the Wall, as displayed in Fig. 4(b). Therefore, the recordings can be used for the verification of the numerical model(s).

The south Circuit Wall in the study area is a heavy masonry retaining system that supports the backfill material. The geometry of the numerical model is based on the architectural representation shown in Fig. 5(a). As displayed in Fig. 5(a), the Wall at this location is based on the inclined bedrock. The inclination of the bedrock is approximately $20^{\circ}$ (Trikkalinos 1977). 
The impact of the special topographic conditions in the dynamic response of the whole Acropolis hill has been highlighted in a recent study (Kapogianni et al. 2020). The twodimensional numerical model depicted in Fig. 5(b) has been developed utilizing the geotechnical finite-element software PLAXIS 2D (Brinkgreve et al. 2010).

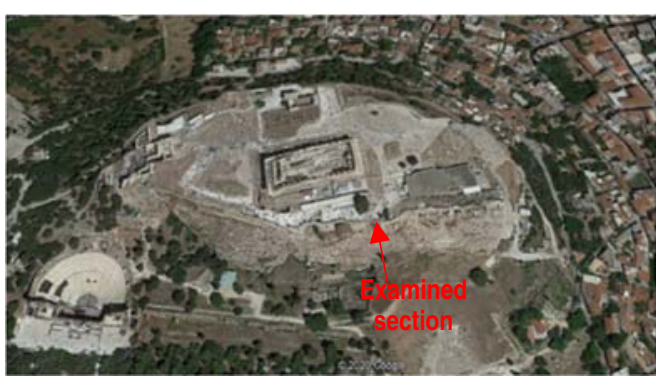

(a)

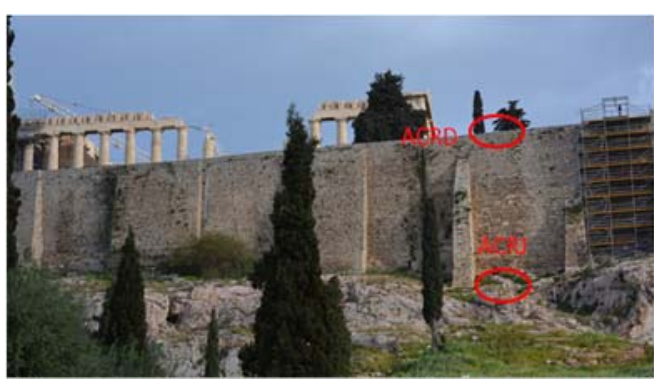

(b)

Fig. 4. (a) Location of the examined section at the south part of Acropolis hill, and (b) installed accelerographs at the base (ACRJ) and at the top (ACRD) of the Wall.

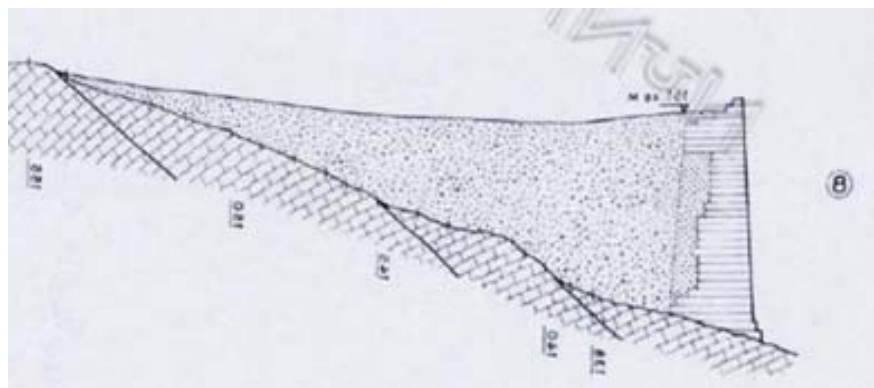

(a)

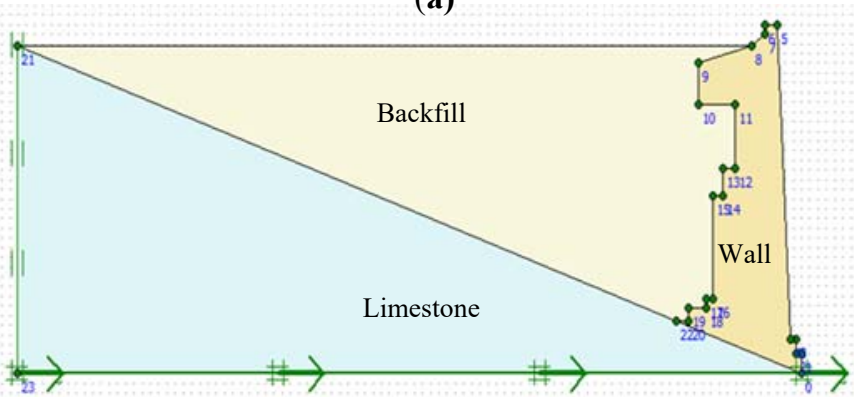

(b)

In the developed numerical model, a uniform material has been used to model the Wall

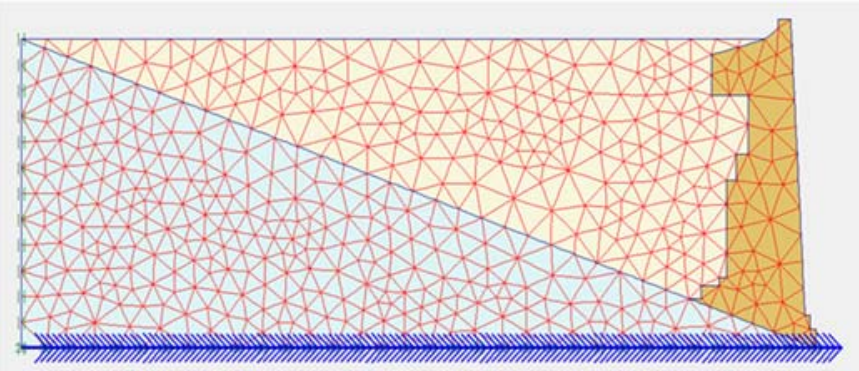

(c)

Fig. 5. (a) Cross section of the examined south Wall section (adopted from Trikkalinos 1977), (b) twodimensional numerical model, and (c) finite-element discretization. section, i.e., not distinguishing different types of materials (stones and mortars). Taking into account aging, damages, interventions, etc. and the limited available geotechnical data from 
the non-uniform backfill and Wall materials, it is very difficult to derive accurate mechanical properties. Despite the simplified approach and the various material and geometrical uncertainties, the adopted numerical methodology can produce quite realistic results. Table 1 presents the mechanical properties of the Wall, the backfill material and the limestone bedrock, which have been taken from a recent study by Psarropoulos et al. (2018).

In addition, as depicted in Fig. 5(c), a sufficient dense mesh has been used with 15-noded triangular finite elements, which exhibit high computational accuracy. The Wall has also been modelled using plane-strain triangular finite elements, which provide a more accurate representation of the complex Wall structure, in terms of its geometry and rigidity, compared to simple beam elements. Since the imposed seismic excitations are characterized by low acceleration levels, the behavior of the materials is realistically considered to be linear elastic. Rayleigh damping, $\xi$, is set equal to $0.5 \%$, in the frequency range between 5 to $10 \mathrm{~Hz}$.

Table 1. Mechanical properties of rock, backfill and the Wall.

\begin{tabular}{lccc}
\hline & Rock & Backfill & Wall \\
\hline Unit weight, $\gamma\left(\mathrm{kN} / \mathrm{m}^{3}\right)$ & 26 & 20 & 26 \\
Shear-wave velocity, $\mathrm{V}_{\mathrm{S}}(\mathrm{m} / \mathrm{s})$ & 1,500 & 300 & 1,090 \\
Young's modulus, E $(\mathrm{MPa})$ & 16,000 & 480 & 7,900 \\
Poisson' s ratio, $v(-)$ & 0.30 & 0.30 & 0.25 \\
\hline
\end{tabular}

The employed numerical approach has been previously validated using the same mechanical and geometrical properties by Psarropoulos et al. (2018). The validation was based on two real seismic excitations from the installed accelerographs at the Wall shown in Fig. 4(b). A comparison was performed in terms of amplification factor (AF) in the frequency domain, which is actually a transfer function that denotes the ratio between the Fourier spectra of the acceleration time-histories at the top and at the base of the Wall due to an imposed excitation. It was proven that the numerical results matched closely the available in-situ measurements, i.e., the AF derived from the recorded data and the numerical analyses exhibited marginal discrepancies. Therefore, based on that realistic modeling approach of the current Wall structural and geotechnical conditions, the current study examines its current dynamic distress and further proposes an efficient and suitable mitigation measure for its seismic protection.

\section{Dynamic response of the Circuit Wall}

\subsection{Dynamic response characteristics}

In order to assess the dynamic response of the system (i.e., rock-backfill-Wall), a Ricker pulse has been used. In general, Ricker pulses cover a sufficiently wide range of frequencies, leading thus to a more realistic calculation of the amplification factor (AF), which can be used to predict the dynamic response of the system for other seismic excitations. Fig. 6(a) presents the acceleration time history of the Ricker pulse. The maximum acceleration of the pulse is set equal to $0.1 \mathrm{~m} / \mathrm{sec}^{2}$. Due to the low acceleration levels, all dynamic analyses can be considered to be linear elastic. The central frequency of the Ricker pulse is selected to be $6 \mathrm{~Hz}$ in order to cover the whole frequency range of interest for the examined case study. Fig. 6(b) depicts the $6 \mathrm{~Hz}$ Ricker Fourier spectrum that has been used for all dynamic analyses. 


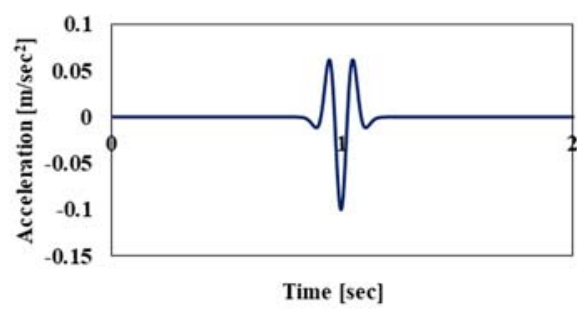

(a)

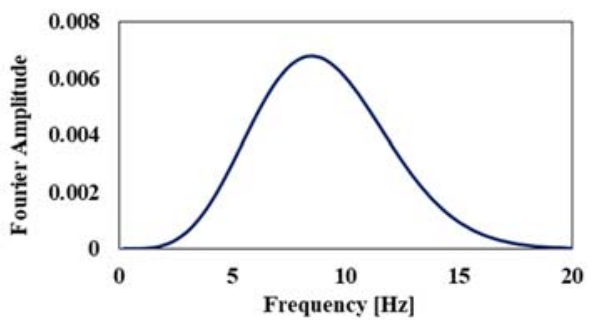

(b)

Fig. 6. (a) Acceleration time history, and (b) Fourier spectrum of the Ricker $6 \mathrm{~Hz}$ pulse excitation.

Fig. 7 presents the acceleration amplification factor (AF) in terms of frequency, which denotes the ratio between the computed Fourier spectra at the top and at the base of the Wall for the imposed Ricker $6 \mathrm{~Hz}$ excitation. It has to be stressed that the accurate assessment of the developed acceleration levels at the top of the hill is crucial for the Acropolis monuments. As it can be observed, the fundamental frequency of the whole system (i.e., rock, backfill material, Wall) is approximately $7.8 \mathrm{~Hz}$, for which the maximum acceleration AF is almost 120 . Hence, the south Circuit Wall is more vulnerable to high-frequency seismic excitations with dominant frequencies close to $8 \mathrm{~Hz}$.

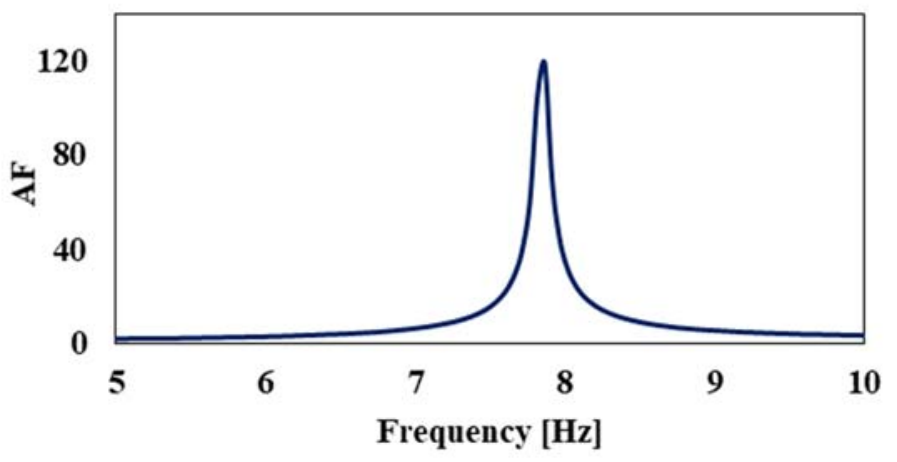

Fig. 7. Acceleration Amplification Factor (AF) for the examined section of the south Circuit Wall for the Ricker $6 \mathrm{~Hz}$ excitation.

\subsection{Dynamic pressures}

The height-wise distribution of the dynamic pressures on the examined section of the south Circuit Wall for the Ricker pulse excitation is presented in Fig. 8. In the lower part of the Wall, near to its base, the dynamic pressures from the backfill material are lower, compared to those in the upper part. Note that in all relevant plots, the pressures are shown only at the backfill, i.e., they are not calculated at the base of the Wall due to the inclined bedrock and the approximately $3 \mathrm{~m}$ "embedment" of the Wall at its lower part, as shown in Fig. 5. It should be mentioned that the pattern of the dynamic pressures depends on the geometry of the Wall and the thickness of the backfill material. Due to the complexity of the geometry of the Wall, the distribution is different from the corresponding one of a typical cantilever wall. Dynamic earth pressures present high values in the upper part of the Wall, due to the inclined bedrock that results in a triangular geometry of the backfill (see Fig. 5). As it can be noticed in Fig. 8, at the thicker upper part of the Wall, the pressures present a maximum value of the order of $25 \mathrm{kPa} / \mathrm{m}$. 


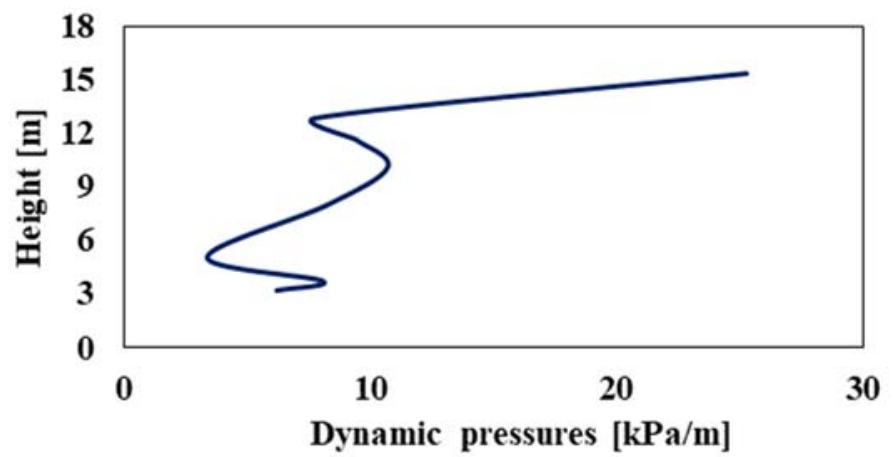

Fig. 8. Height-wise distribution of the dynamic pressures on the examined section of the south Circuit Wall for the Ricker excitation.

In the sequence, the Pressure Amplification Factor (PAF) is introduced, which can be used to assess the variation and potential amplification of dynamic earth pressures in the frequency domain (Psarropoulos et al. 2009). This parameter is defined as follows:

$$
P A F=\frac{F F T\left[\Delta P_{A E}(t)\right]}{F F T[A(t)]}
$$

where $\operatorname{FFT}\left[\Delta P_{A E}(t)\right]$ is the Fourier spectrum of the normalized induced dynamic earth force time history $\triangle P_{A E}(t)$ and $F F T[A(t)]$ is the Fourier spectrum of the acceleration time history imposed at the base of the Wall (i.e., the Ricker pulse excitation shown in Fig. 6(b)). It is noted that PAF, being -analogously to AF- a transfer function in the frequency domain, can provide a reliable assessment of the distress levels of the Wall (in terms of earth pressures) by utilizing the Fourier spectrum of any seismic excitation.

It is evident from Fig. 9 that PAF reaches its maximum value at the fundamental frequency of the rock-backfill-Wall system. Hence, for high-frequency excitations (i.e., close to $8 \mathrm{~Hz}$ ), the dynamic pressures on the Wall present their highest values, which may lead to severe damages of the Wall for extreme seismic intensity levels. In contrast, PAF exhibits low values for low- to medium-frequency excitations (i.e., up to $6 \mathrm{~Hz}$ ). Thus, comparatively less amplification is expected regarding the dynamic pressures exerted on the Wall.

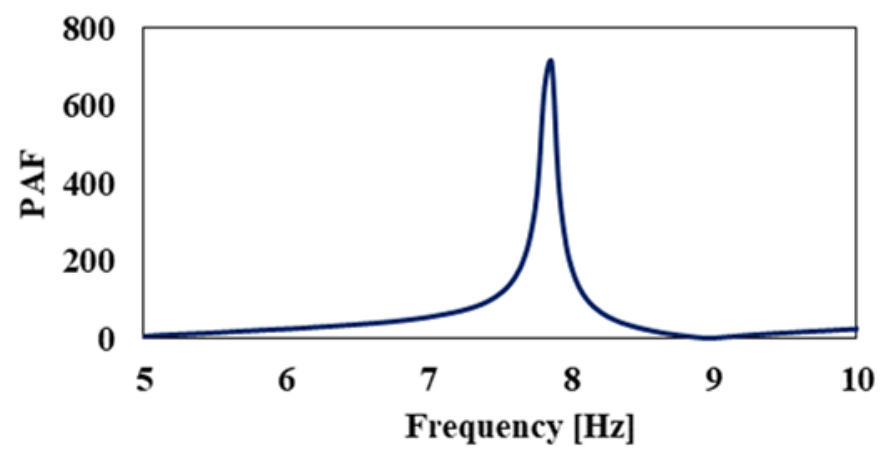

Fig. 9. Pressure Amplification Factor (PAF) in the frequency domain for the south Circuit Wall section under Ricker pulse excitation. 


\section{Seismic mitigation measures}

Old masonry retaining walls, such as the Wall at the Acropolis hill, are sensitive structures that are quite vulnerable to seismic loading. Therefore, their protection should be ensured. The seismic behavior of such retaining structures depends not only on their mechanical and geometrical properties but on the characteristics of: (a) the backfill material(s), and (b) the seismic excitation (i.e., peak values, frequency content, duration).

As the aim of the engineers is to reduce the anticipated dynamic earth-pressures, the protection of old masonry retaining walls can be achieved by the application of various inclusions between the wall and the retained soil, such as the proposed expanded polystyrene (EPS). Since any intervention modifies the natural frequencies of the system, the impact of any inclusion may be beneficial or detrimental, depending on the circumstances. Therefore, a caseby-case study is required in order to choose the optimal mitigation measure.

\subsection{Application of the EPS along the total height of the Wall}

The improvement of the seismic response, i.e., the reduction of the dynamic earth pressures on the Circuit Wall, is achieved herein via the application of an EPS inclusion between the Wall and the backfill material. The current investigation includes two types of EPS with different densities. The main mechanical properties are presented in Table 2. Evidently, EPS39 is more stiff, due to the higher Young's modulus. A parametric analysis has been conducted considering three different average thicknesses of EPS: $2.4 \mathrm{~m}, 4.3 \mathrm{~m}$, and $6.3 \mathrm{~m}$, as presented in Fig. 10. Evidently, the thickness of EPS between the Wall and the backfill material cannot be uniform due to the complex geometry of the Wall.

Note that in reality, potential sliding between EPS blocks as well as between EPS and backfill and EPS and Wall may occur. These interactions can be modelled via interface elements or contact constraints using realistic parameters (e.g., friction angle values) that can be obtained from physical tests. However, there is a great variation of the interface properties, depending on the type of different materials (EPS-EPS, EPS-soil, EPS-concrete, etc.), the density of EPS, the applied normal loads on the geofoam blocks, etc. On the other hand, EPS blocks can be quite easily tied together using stainless steel connectors (such as barbed steel plates), while similar connectors (e.g., simple steel rods, which apart of friction exhibit pull-out resistance) can be used to ensure their full contact with the soil, i.e., the avoidance of sliding/debonding. Moreover, the EPS blocks are "interlocked", i.e., not placed exactly on top of each other following the same vertical alignment.

In addition, EPS block surfaces that are in contact with the soil and the Wall can be deliberately roughened to increase the friction at the soil-EPS interfaces, while geogrids/geomembranes can also be placed between soil and EPS blocks. In general, EPS has been applied in many geotechnical projects and there exist relevant guidelines. Thus, very detailed practical aspects are not included herein. Therefore, taking into account the various uncertainties related to Wall and the aforementioned technical details regarding practical implementation, this preliminary investigation considers that geofoam blocks form a monolithic, homogeneous mass, perfectly tied with the backfill and the Wall materials. 
Table 2. Mechanical properties of EPS19 and EPS39.

\begin{tabular}{lcc}
\hline & EPS19 & EPS39 \\
\hline Young's modulus, E (MPa) & 4 & 10.3 \\
Density, $\rho\left(\mathrm{kg} / \mathrm{m}^{3}\right)$ & 19 & 39 \\
Poisson' s ratio, $v(-)$ & 0.05 & 0.05 \\
\hline
\end{tabular}

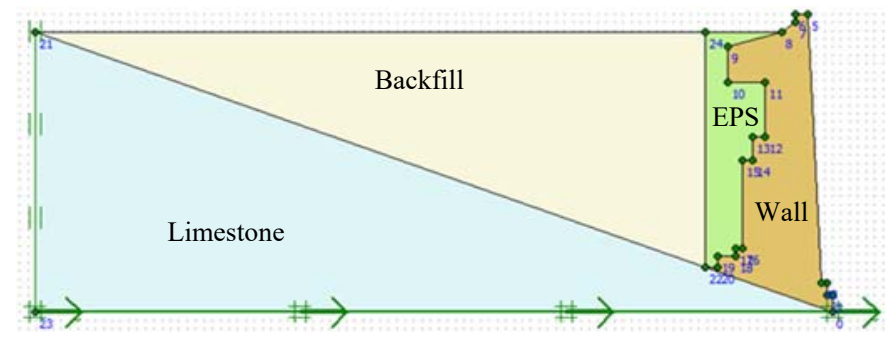

(a)

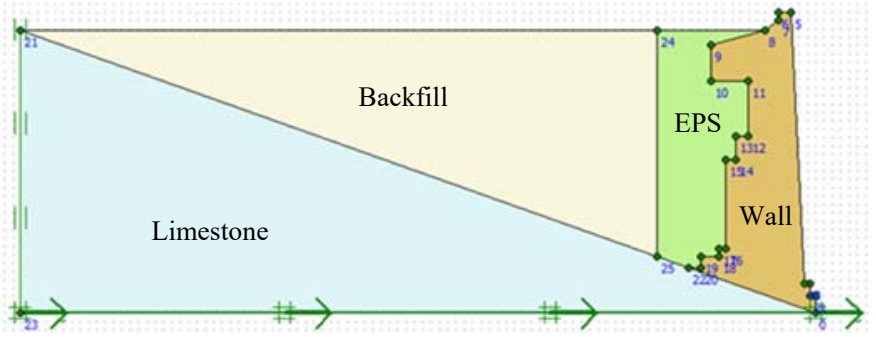

(b)

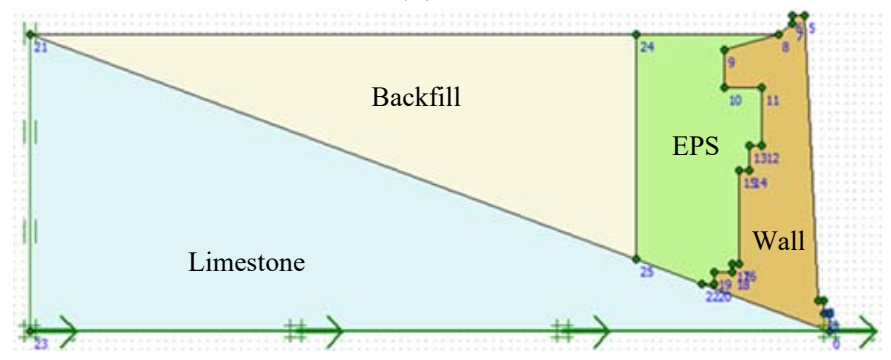

(c)

Fig. 10. South Circuit Wall section with EPS inclusion along its height with average thickness: (a) $2.4 \mathrm{~m}$, (b) $4.3 \mathrm{~m}$, (c) $6.3 \mathrm{~m}$.

The behavior of EPS is considered to be linear elastic, while its damping, according to related studies, is very small for low strain levels (Athanasopoulos et al., 1999). Thus, Rayleigh damping, $\xi$, is considered to be equal to $0.5 \%$, as for the other materials. Apart from the inclusion of EPS, the developed two-dimensional numerical models are similar to the reference model describing current Wall status in Fig. 5. More specifically, Fig. 10 displays the numerical models when EPS is installed along the total height of the Wall, for the three average EPS thickness. Similar to the backfill and the Wall, EPS is also modeled with plane-strain elements. For the discretization of all models, a dense mesh is used with 15-noded triangular plane-strain elements, which exhibit high computational accuracy. Lastly, the Ricker pulse shown in Fig. 6 has been used for all dynamic analyses, as its frequency content is suitable both for the initial and all modified (due to EPS inclusion) models of the Wall. 


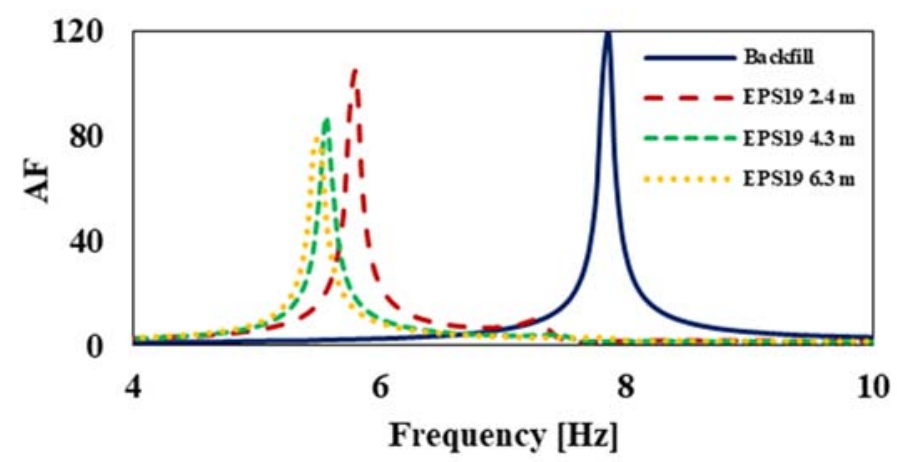

(a)

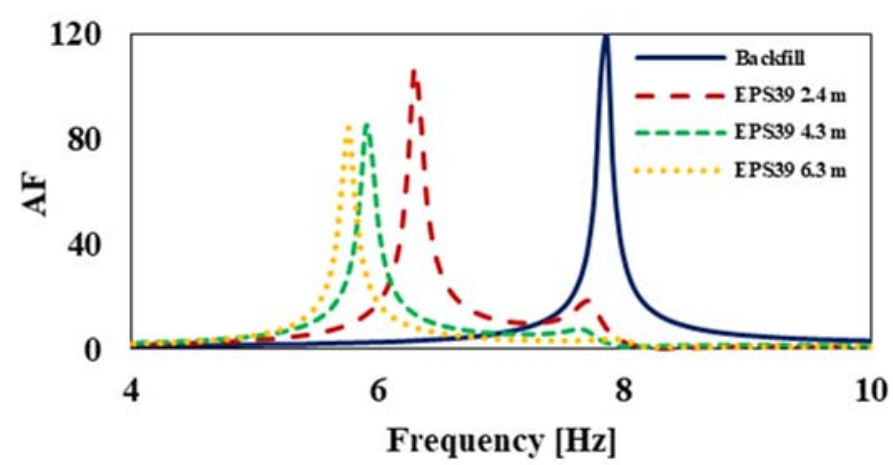

(b)

Fig. 11. Amplification Factors (AF) of the examined south Circuit Wall section with: (a) EPS19 and (b) EPS39.

Figs. 11 (a) and (b) present the amplification factors (AF) in the frequency domain for the cases where EPS19 and EPS39 blocks have been placed between the Wall and the backfill. As it can be noticed, the application of both types EPS increases the flexibility of the system and reduces its fundamental frequency. The flexibility of the system is increased for higher EPS thickness; however, as the EPS thickness further increases (i.e., from $4.3 \mathrm{~m}$ to $6.3 \mathrm{~m}$ ), the reduction of the fundamental frequency is smaller. Comparing the two types of EPS, it can be observed that the EPS19 contributes to a greater reduction of the fundamental frequency for all the examined thicknesses. As it can be observed, the application EPS decreases the AF for all the examined thickness values in a similar manner for EPS19 and EPS39 in all cases.

Figs. 12 (a) and (b) illustrate the distribution of dynamic pressures on the Wall for the two types of EPS and the three examined thickness values when the EPS is applied along the entire height of the Wall, compared to the initial dynamic earth pressures. The shape of the distribution does not seem to be significantly affected compared to the initial case, i.e., without the addition of EPS blocks. Dynamic pressures are also greater at the upper part of the Wall for all the examined thickness values. However, a substantial reduction of the dynamic pressures is observed due to the application of EPS. The reduction is bigger as the thickness of the EPS increases from $2.4 \mathrm{~m}$ to $4.3 \mathrm{~m}$. As the thickness of both EPS19 and EPS39 further increases from $4.3 \mathrm{~m}$ to $6.3 \mathrm{~m}$, the beneficial impact of EPS is smaller. By comparing the two types of EPS, it 
can be seen that EPS19 provides a greater reduction of dynamic pressures on the Wall for all the examined thickness values.

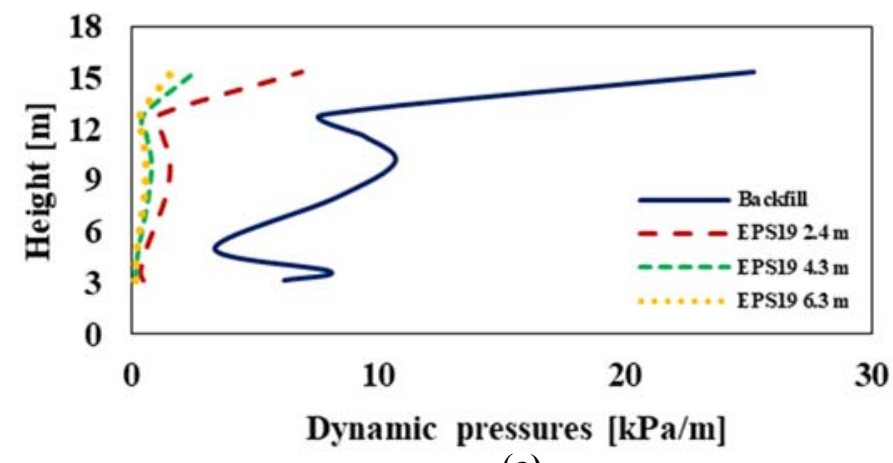

(a)

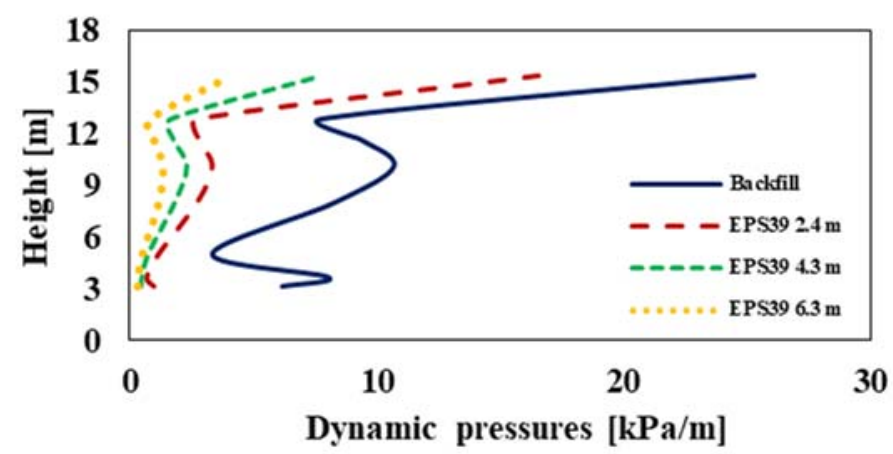

(b)

Fig. 12. Height-wise distribution of the dynamic pressures for: (a) EPS19 and (b) EPS39.

The variation of the PAF in the frequency domain, when the EPS is installed along the total height of the Wall, is depicted in Figs. 13 (a) and (b) for the two EPS types compared to the PAF of the reference backfill model. Obviously, the maximum PAF occurs at the fundamental frequency of each model, which is influenced by the thickness and EPS type. The addition of EPS between the Wall and the backfill leads to a reduction of the maximum PAF. The reduction is bigger when the EPS thickness is increased. The only exception is when using EPS39 with an average thickness of $2.4 \mathrm{~m}$, in which an increase of the PAF is observed. Therefore, it can be concluded that an EPS inclusion with small thickness is neutral or even detrimental for the seismic distress of the Wall. In contrast, for greater EPS thickness, a substantial reduction of the PAF value is observed, especially when applying the softer geofoam material.

In general, EPS19 provides a better protection to the Wall against dynamic loads compared to EPS39. Hence, taking into account the minimization of backfill excavations and removal as well as EPS material quantities, the use of EPS19 with a $4.3 \mathrm{~m}$ thickness is considered preferable. 


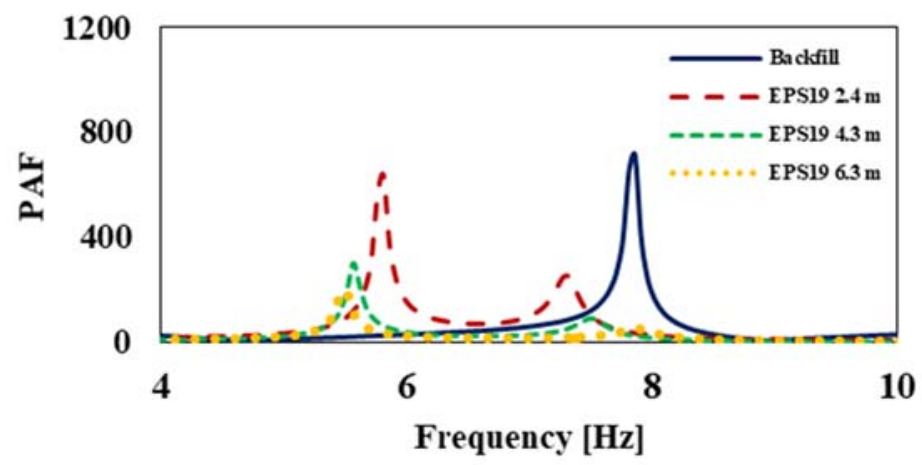

(a)

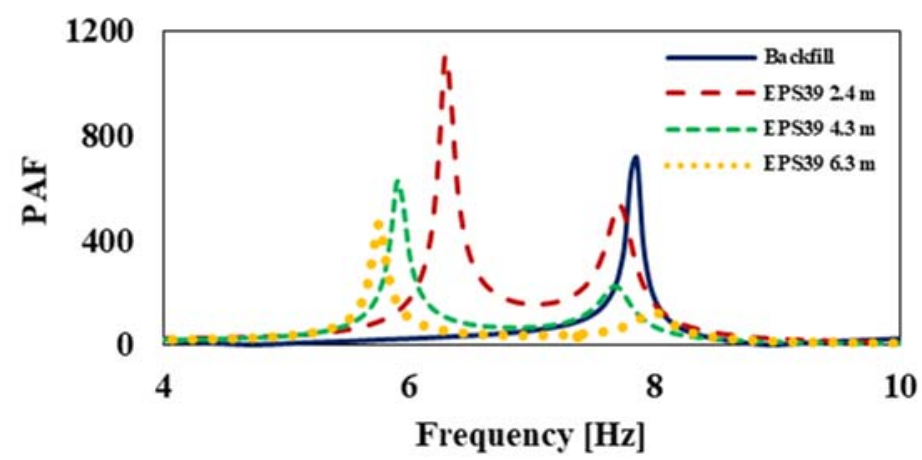

(b)

497

498

499

500

501

502

503

504

505

506

507

508

509

510

511

512

513

514

515

516

517

518

Fig. 13. Pressure Amplification Factors (PAF) for: (a) EPS19 and (b) EPS39.

\subsection{Application of EPS at the upper part of the Wall}

In this section, the application of EPS at the upper part of the Wall is investigated in order to determine its potential impact on the dynamic pressures. In this case, the EPS is placed up to 7.9 meters below the surface of the backfill, thus covering almost $45 \%$ of the total Wall's height. The purpose of this configuration is to further improve -if possible- the seismic response of the Wall and mainly to reduce the total time and cost by reducing the required quantities of EPS blocks as well as the required excavations and backfill removal from the Acropolis hill, which are not easy tasks. The type of EPS that has been used is EPS19, with the three average thicknesses of $2.4 \mathrm{~m}, 4.3 \mathrm{~m}$, and $6.3 \mathrm{~m}$. The resulting numerical models are similar to the ones shown in Fig. 10, while the same Ricker pulse has been used. Figs. 14 (a), (b) and (c) present the numerical model when EPS is placed at the upper part of the Wall.

Firstly, the dynamic response of the system is examined in terms of AF in the frequency domain. The variation of AF is presented in Fig. 15 in the case of EPS19 inclusion at the upper part of the Wall. The application of EPS19 decreases the fundamental frequency, as it reduces the mass and increases the flexibility of the system. As in the previous case with EPS inclusion along the whole Wall height, in the case of greater EPS thickness (i.e., $4.3 \mathrm{~m}$ and $6.3 \mathrm{~m}$ ) the differences in the fundamental frequencies of the system are marginal. As it was expected, the fundamental frequency of the system is bigger compared to the approach when the EPS is placed along the total height of the Wall; nonetheless, an analogous reduction of AF is obtained. 


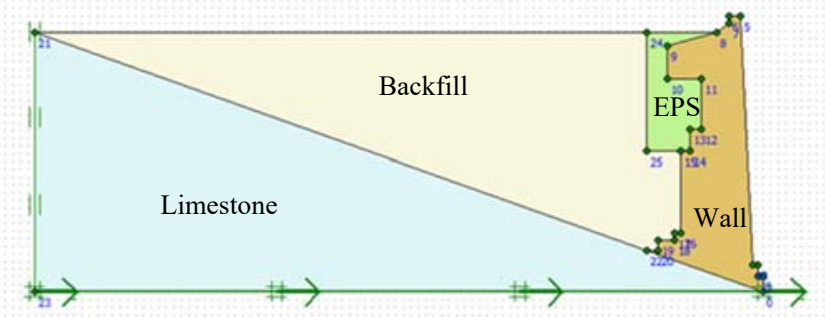

(a)

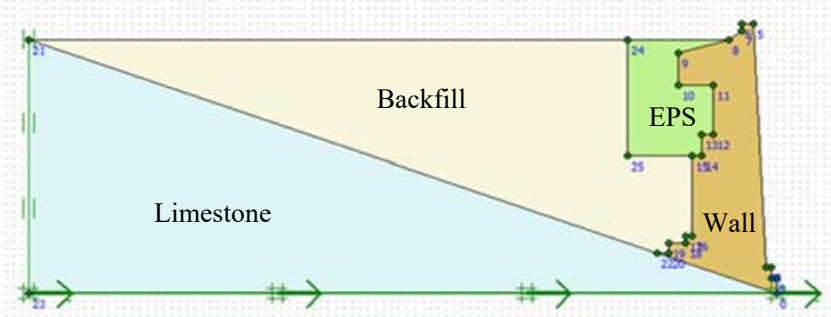

(b)

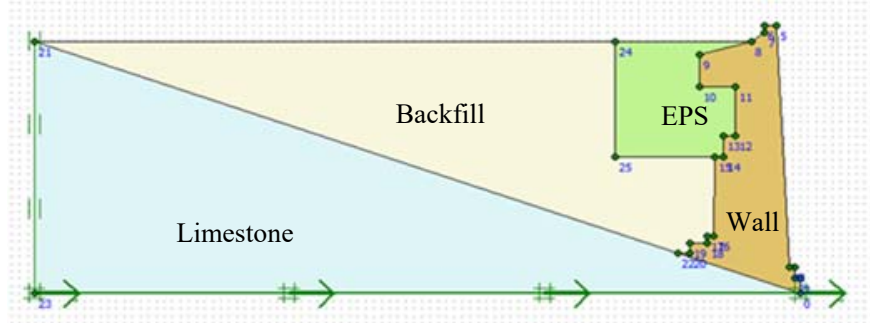

(c)

Fig. 14. South Circuit Wall section with EPS at its upper part and average thickness: (a) $2.4 \mathrm{~m}$, (b) $4.3 \mathrm{~m}$, (c) $6.3 \mathrm{~m}$.

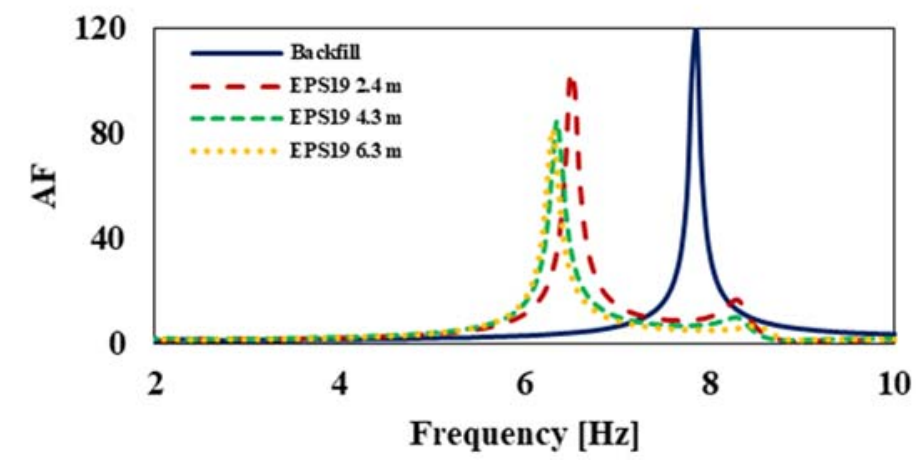

Fig. 15. Amplification Factors (AF) of the examined south Circuit Wall section mitigated at its upper part with EPS19.

As it can be noticed by observing Fig. 16, the shape of the height-wise dynamic pressures distribution when the EPS is applied at the upper part of the Wall, is completely different compared to the initial backfill pressures. More specifically, dynamic pressures are smaller at the upper part which is covered with EPS19 blocks, while at the lower part dynamic pressures exhibit a dramatic increase compared to the current backfill conditions. Maximum dynamic pressures occur at a height between $6 \mathrm{~m}$ and $8 \mathrm{~m}$ from the base of the Wall. The increase of the 
dynamic pressures at the lower part of the Wall can be attributed to the accumulation of seismic waves in the area between the inclined bedrock, the EPS inclusion and the Wall. The seismic waves are trapped and reflected within this area, amplifying thus the dynamic pressures on the Wall. These trends are observed for all the examined EPS thickness values. Nonetheless, as the thickness of the EPS19 increases, the dynamic pressures are reduced along the whole height of the Wall.

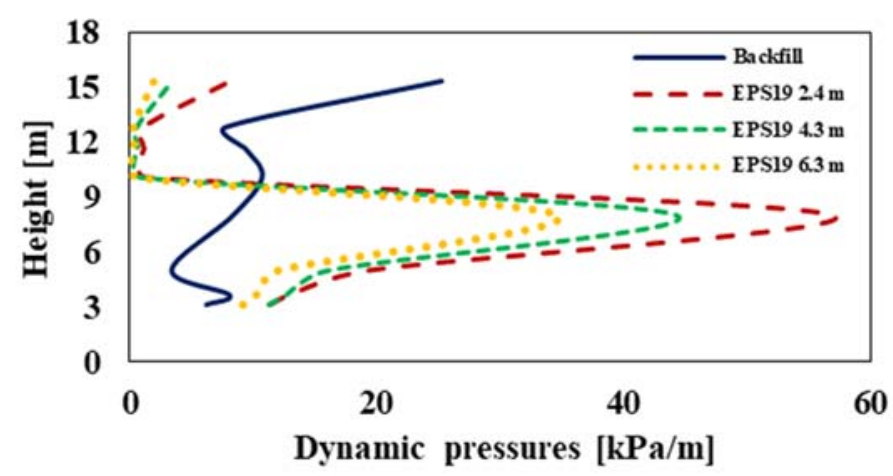

Fig. 16. Height-wise distribution of the dynamic pressures for EPS19 inclusion at the upper part of the south Circuit Wall section.

Fig. 17 presents the variation of the PAF in the frequency domain when the EPS19 is placed at the upper part of the Wall, for all the examined EPS thicknesses. The maximum PAF occurs at the fundamental frequency for each model. A significant increase is observed for the maximum PAF with the addition of EPS19 compared to the reference case irrespective of inclusion thickness. The increase is higher for small EPS thickness. Moreover, compared to the soil model, PAF reaches higher values throughout the frequency domain. Hence, the inclusion of soft geofoam at the upper part of the Wall is highly detrimental, while the application of stiffer EPS39 leads to even worse results and it should also be avoided.

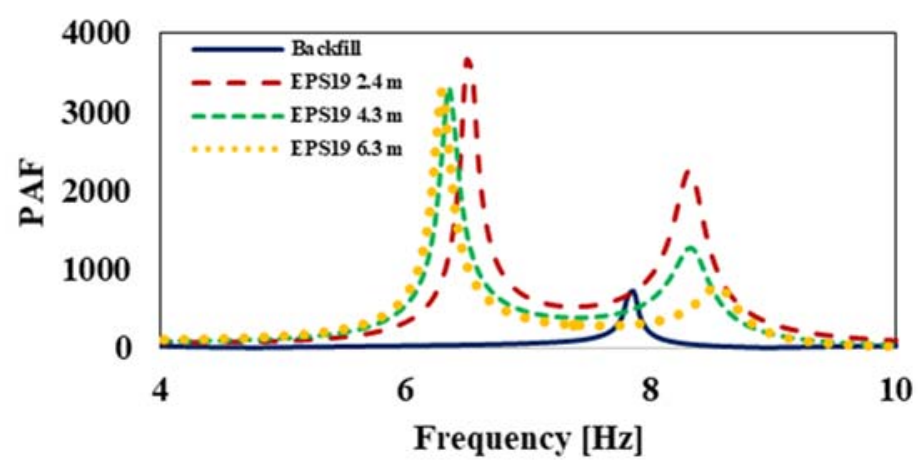

Fig. 17. Pressure Amplification Factors (PAF) of the examined south Circuit Wall section mitigated with EPS19 at its upper part.

\subsection{Application of EPS at the lower part of the Wall}

In the sequence, the dynamic response of the system has been examined for the case when EPS blocks are placed at the lower part of the Circuit Wall. Both EPS19 and EPS39 have been used for all the examined average thickness values (i.e., $2.4 \mathrm{~m}, 4.3 \mathrm{~m}, 6.3 \mathrm{~m}$ ) as in the previous 
cases. EPS is considered to be placed up to $10.6 \mathrm{~m}$ from the base of the Wall, covering almost $60 \%$ of its total height. The three corresponding numerical models presented in Figs. 18(a), (b), and (c), have been developed in the same manner as when EPS is applied along the total height.

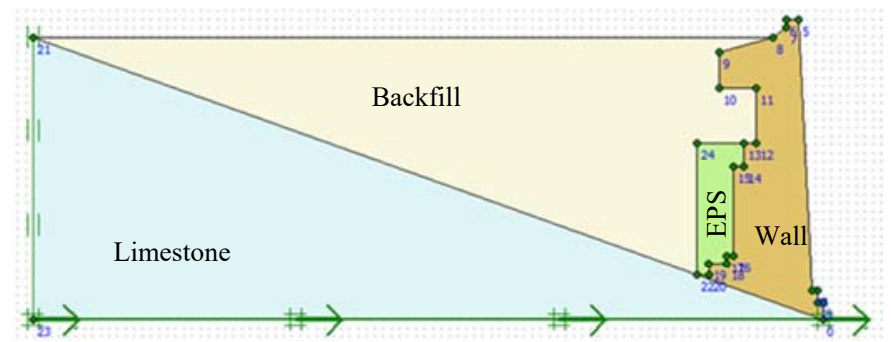

(a)

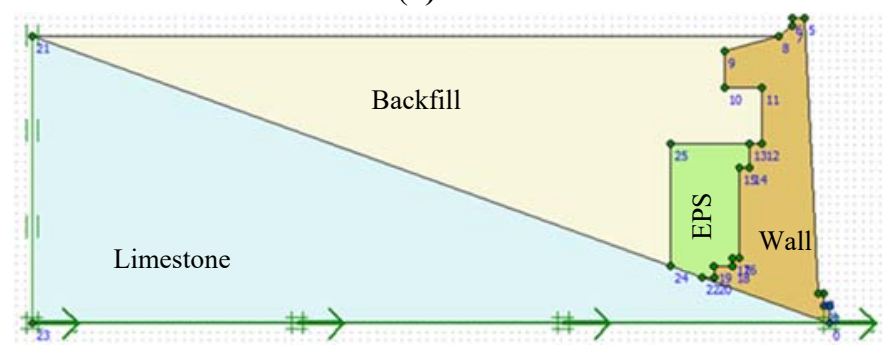

(b)

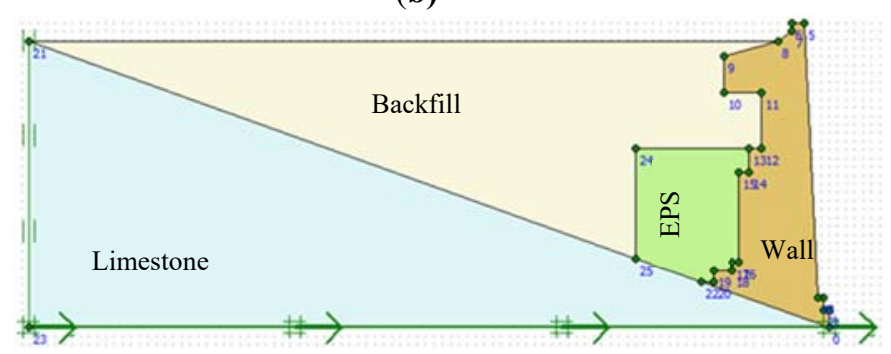

(c)

Fig. 18. South Circuit Wall section with EPS at its lower part and average thickness:

(a) $2.4 \mathrm{~m}$, (b) $4.3 \mathrm{~m}$, (c) $6.3 \mathrm{~m}$.

Fig. 19 depicts the variation of AF when EPS19 and EPS39 blocks are applied at the lower part of the Wall, for all examined thickness values, and also for the current backfill conditions without EPS. As it can be noticed, the Wall has a similar seismic response for both EPS19 and EPS39, as the differences are insignificant. The application of EPS makes the system more flexible, reducing thus its fundamental frequency. When the thickness of EPS is increased, the reduction of the fundamental frequency is higher. The fundamental frequency for each average thickness is bigger compared to the corresponding ones when the EPS is applied along the entire height of the Wall or only at its upper part. The values of the AF are considerably lower compared to the two previously examined cases of EPS height-wise configuration for all thickness values, while an almost identical response for both EPS19 and EPS39 types is observed. 


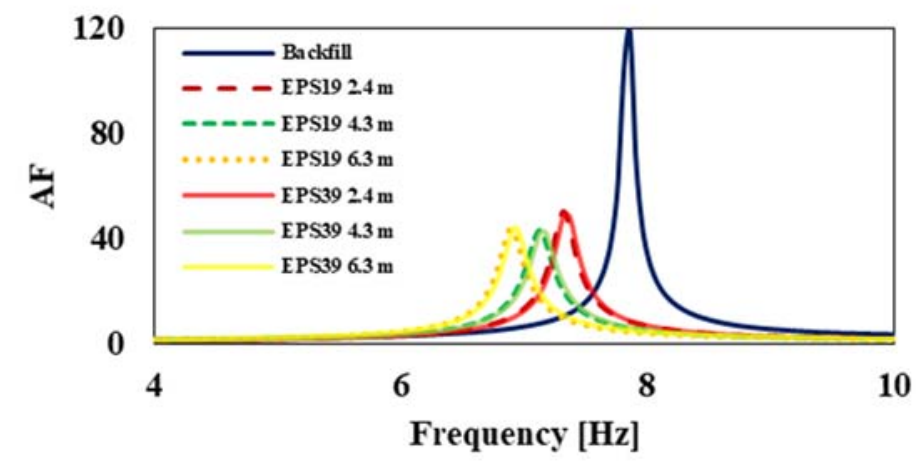

585

Fig. 19. Amplification Factors (AF) of the examined south Circuit Wall section mitigated at its lower part.

The height-wise dynamic pressures distribution when either EPS19 or EPS39 are applied at the lower part of the Wall are presented in Fig. 20. As it can be observed, the distribution is quite similar for EPS19 and EPS39, for all EPS thickness values. In contrast, it presents significant differences compared to the initial model without EPS. At the lower part of the Wall, where EPS inclusion is placed, dynamic pressures are substantially reduced compared to the current soil conditions. On the other hand, in the upper part they become much higher. This increase can be attributed to the reflections of seismic waves within the area between the Wall and the EPS at the upper part of the backfill material. In addition, like in the EPS layouts presented in previous sections, the reduction of the dynamic pressures along the whole height of the Wall is increased for larger EPS thickness. Nevertheless, the increase is lower compared to the case in which the EPS is placed only at the upper part, due to the greater thickness of the backfill material behind the Wall.

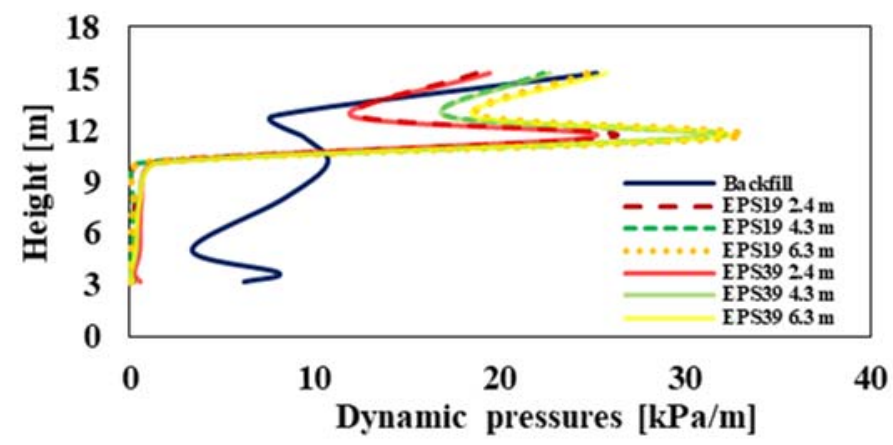

Fig. 20. Height-wise distribution of the dynamic pressures with EPS at the lower part of the south Circuit Wall section.

The variation of PAF in the frequency domain when EPS19 and EPS39 are applied at the lower part of the Wall is depicted in Fig. 21. As it can be easily observed, PAF values are approximately identical for EPS19 and EPS39. The maximum PAF, which occurs at the fundamental frequency for each EP-retrofitted model, is smaller compared to the reference backfill model. Nevertheless, in contrast to the previous two EPS configurations, PAF is becoming slightly higher as the thickness increases, i.e., when the EPS is applied at the bottom 
of the Wall, a smaller EPS thickness contributes to a lower seismic distress of the Wall. Lastly, it is also worth noting that compared to the case that EPS is applied along the total height of the Wall, PAF is bigger for all EPS thickness values.

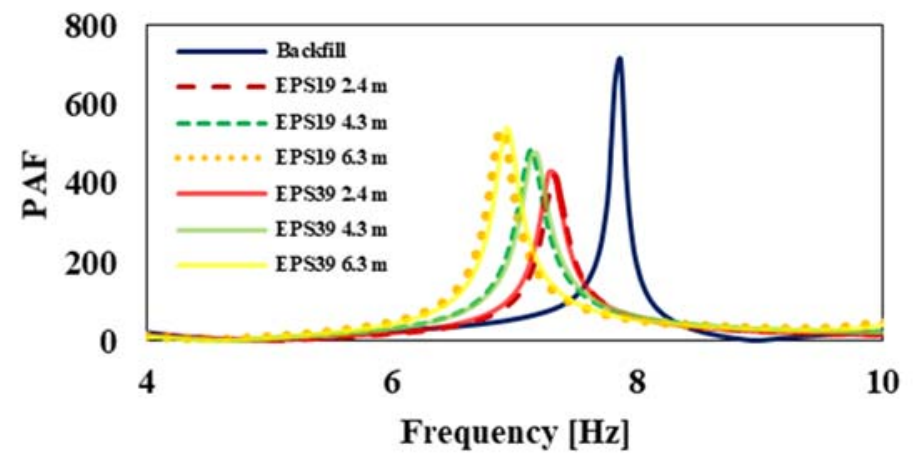

Fig. 21. Pressure Amplification Factors (PAF) of the examined south Circuit Wall section mitigated with EPS at its lower part.

\section{Conclusions}

The present study investigates the dynamic distress of the south Circuit Wall of Acropolis and the impact of EPS inclusions as potential seismic mitigation measure. For this purpose, finite-element models for a critical section of the Wall have been developed and a series of linear elastic dynamic analyses has been performed. Based on the calculation of the fundamental frequency of the system rock-backfill-Wall, which is approximately equal to 7.8 $\mathrm{Hz}$, the Wall can be affected more by high-frequency near-field ground motions due to potential resonance phenomena. The inclusion of the EPS between the Wall and the backfill increases the flexibility of the system, thus, reduces its fundamental frequency. In addition, larger EPS thickness further increases the flexibility of the system. On the other hand, the inclusion of stiffer EPS (e.g., EPS39) is less efficient compared to the softer geofoam (e.g., EPS19). The reduction of the fundamental frequency is greater when EPS is applied along the total height of the Wall and smaller when the EPS is applied only at its lower or upper part. In all the examined cases, EPS reduces AF (i.e., the acceleration levels at the top of the hill) for high-frequency seismic excitations with dominant frequencies in the range of 7 to $8 \mathrm{~Hz}$.

The height-wise distribution of the dynamic pressures is significantly affected by the complex geometry of the Wall. Dynamic pressures of the earth fill are smaller at the base of the Wall and they are higher at the top. The inclusion of EPS along the total height of the Wall reduces substantially the dynamic pressures compared to the ones due to backfill, but does not alter their distribution. In contrast, when EPS is applied only at the upper part or at the lower part, the distribution is much different from the current soil conditions. In these cases, dynamic pressures are significantly increased at the part of the Wall that is not protected with EPS. It is noted that the type and the thickness of the EPS do not alter the pattern of the dynamic pressures, but only their values.

In all cases, the maximum dynamic pressures occur at the fundamental frequency of the system. The application of the EPS along the entire height reduces the dynamic pressures on the Wall, mainly for larger thickness and for softer EPS material. In contrast, when stiffer EPS 
with small thickness is used, a minor increase of the dynamic pressures is observed. Moreover, when EPS is placed only at the upper part of the Wall, a significant increase of the dynamic pressures is noticed. Therefore, the potential application of EPS only at the upper part of the Wall may have a detrimental impact and should be avoided. The application of EPS at the lower part of the Wall leads to a reduction of the dynamic pressures at the protected part and it is more efficient for small thickness of EPS inclusion. In this case, the differences between the two EPS types that have been examined are negligible.

Conclusively, the optimal intervention to protect the Wall is the application of a soft type of EPS (e.g., EPS19) along the total height of the Wall and having a high thickness (e.g., $4.3 \mathrm{~m}$ or $6.3 \mathrm{~m}$ ). Alternatively, soft EPS material can be placed only at the lower part of the Wall with a small EPS thickness (e.g., $2.4 \mathrm{~m}$ ). Nevertheless, given the fact that the Circuit Wall has great variations in materials and geometry, the present study should be extended by developing more elaborate three-dimensional models in order to examine more accurately the impact of the proposed EPS inclusion configurations.

\section{Declarations}

\section{Funding}

This research was performed without any funding or grants from any institutions or individuals.

\section{Conflicts of interest/Competing interests}

The authors have no conflicts of interest to declare that are relevant to the content of this article.

\section{Availability of data and material}

Additional information can be provided upon request.

\section{Code availability}

Not applicable.

\section{Authors' contributions}

All authors contributed during the preparation of this work. Manolis Katsirakis: Conceptualization, Methodology, Software, Validation, Investigation, Writing - Original Draft, Visualization. Yiannis Tsompanakis: Conceptualization, Investigation, Writing - Review \& Editing, Supervision, Project administration, Visualization. Prodromos N. Psarropoulos: Conceptualization, Investigation, Writing - Review \& Editing, Visualization.

\section{References}

Ambraseys N, Psycharis IN (2012) Assessment of the long-term seismicity of Athens from two classical columns. Bull Earthq Eng 10(6):1635-1666. https://doi.org/10.1007/s10518012-9388-1 
Athanasopoulos GA, Pelekis PC, Xenaki VC (1999) Dynamic properties of EPS geofoam: an experimental investigation. Geosynth Int 6(3):171-194. https://oi.org/ 10.1680/gein.6.0149

Athanasopoulos GA, Nikolopoulou CP, Xenaki VC S VD (2007) Reducing the seismic earth pressure on retaining walls by EPS geofoam buffers-numerical parametric study. In: Proceedings of the Geosynthetics Conference, Washington, DC. pp 16-19

Athanasopoulos-Zekkos A, Lamote K, Athanasopoulos GA (2012) Use of EPS geofoam compressible inclusions for reducing the earthquake effects on yielding earth retaining structures. Soil Dyn Earthq Eng 41:59-71. https://doi.org/10.1016/j.soildyn.2012.05.004

Brinkgreve RBJ, Swolfs WM, Engin E, Waterman D, Chesaru A, Bonnier PG, Galavi V (2010) PLAXIS 2D 2010. User manual, Plaxis BV.

Dabiri R, Hasanpouri Notash N (2020) Evaluation of geofoam effects on seismic response in cantilever retaining wall. Geotech Geol Eng 38(2):2097-2116. https://doi.org/10.1007/s10706-019-01151-1

EC8 (2004) Eurocode 8: Design of structures for earthquake resistance - Part 1: General rules, seismic actions and rules for buildings (EN 1998-1: 2004). CEN, Brussels, Belgium

Egglezos D, Ioannidou M, Moullou D, Kalogeras I (2013) Geotechnical issues of the Athenian Acropolis. Geotech Herit 13-48. https://doi.org/10.1201/b14965-3

Eleftheriou V (2015) Protection of the Rock and the Fortification Walls of the Acropolis. Works accomplished and future projects. Acrop Restor News 10-15:11-14

Higgins M, Higgins R (1996) Geological companion to Greece and the Aegean, London. Gerald Duckworth Co 26-31

Kapogianni E, Kalogeras I, Psarropoulos PN, Michalopoulou D, Eleftheriou V, Sakellariou M (2019) Suitability of optical fibre sensors and accelerographs for the multi-disciplinary monitoring of a historically complex site: The case of the Acropolis Circuit Wall and Hill. Geotech Geol Eng 37:4405-4419. https://doi.org/10.1007/s10706-019-00917-x

Kapogianni E, Psarropoulos PN, Kokoris D, Kalogeras I, Michalopoulou D, Eleftheriou V, Sakellariou M (2020) Impact of local site conditions on the seismic response of the Athenian Acropolis Hill. Geotech Geol Eng. https://doi.org/10.1007/s10706-020-015898

Koukis G, Pyrgiotis L, Kouki A (2015) The acropolis hill of Athens: Engineering geological investigations and protective measures for the preservation of the site and the monuments. Eng Geol Soc Territ 8:89-93. https://doi.org/10.1007/978-3-319-09408-3_12

Kramer S (1996) Geotechnical earthquake engineering.Upper Saddle River, New Jersey: Prentice Hall

Mononobe N, Matsuo H (1929) On the determination of earth pressure during earthquake. In: Proceedings of the World Engineering Conference, Tokyo, Japan. Vol. 9 paper no. 388

Okabe S (1926) General theory of earth pressures, J Jpn Soc Civil Eng 12(1).

Psarropoulos P, Kapogianni E, Kalogeras I, Michalopoulou D, Eleftheriou V, Dimopoulos G, Sakellariou M (2018) Seismic response of the Circuit Wall of the Acropolis of Athens: Recordings versus numerical simulations. Soil Dyn Earthq Eng 113:309-316. https://doi.org/10.1016/j.soildyn.2018.04.003

Psarropoulos PN, Klonaris G, Gazetas G (2005) Seismic earth pressures on rigid and flexible retaining walls. Soil Dyn Earthq Eng 25(7-10):795-809. https://doi.org/10.1016/j.soildyn.2004.11.020 
Psarropoulos PN, Tsompanakis Y, Papazafeiropoulos G (2009) Effects of soil non-linearity on the seismic response of restrained retaining walls. Struct Infrast Eng 7(12):1-12. https://doi.org/10.1080/15732470903419677

Seed HB, Whitman RV (1970) Design of earth retaining structures for dynamic loads. In: ASCE speciality conference, lateral stresses in the ground and design of Earth retaining structures. Cornell Univ., Ithaca. pp 103-147

Trikkalinos IK (1977) Remarks on the published study on the geology of the Acropolis. Proc Acad Athens 12:311-342

Veletsos AS, Younan AH (1994) Dynamic soil pressures on rigid vertical walls. Earthq Eng Struct Dyn 23(3):275-301. https://doi.org/10.1002/eqe.4290230305

Veletsos AS, Younan AH (1997) Dynamic response of cantilever retaining walls. J Geotech Geoenvironmental Eng 123(2):161-172. https://doi.org/10.1061/(asce)10900241(1997)123:2(161)

Wood JH (1973) Earthquake-induced soil pressures on structures. Rep. No. Earthquake Engineering Research Laboratory (EERL) 73-05, California Institute of Technology, Pasadena, CA.

Zarnani S, Bathurst RJ (2007) Experimental investigation of EPS geofoam seismic buffers using shaking table tests. Geosynth Int 14(3):165-177. https://doi.org/10.1680/gein.2007.14.3.165

Zarnani S, Bathurst RJ (2009) Numerical parametric study of expanded polystyrene (EPS) geofoam seismic buffers. Can Geotech J 46(3):318-338. https://doi.org/10.1139/T08-128 


\section{Figures}

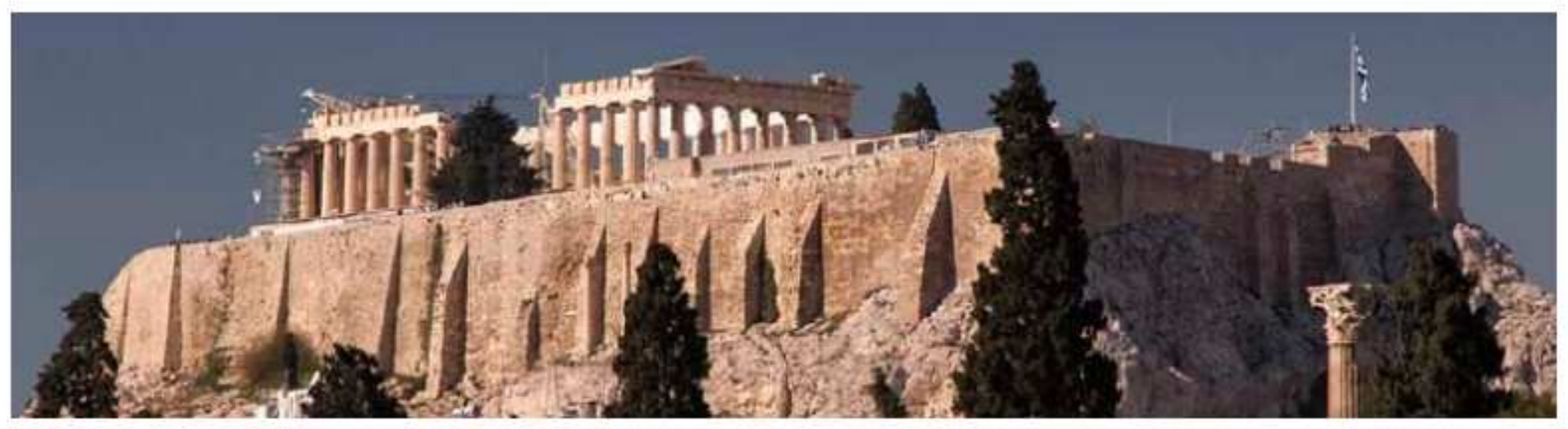

\section{Figure 1}

View of the south Circuit Wall of Acropolis of Athens.

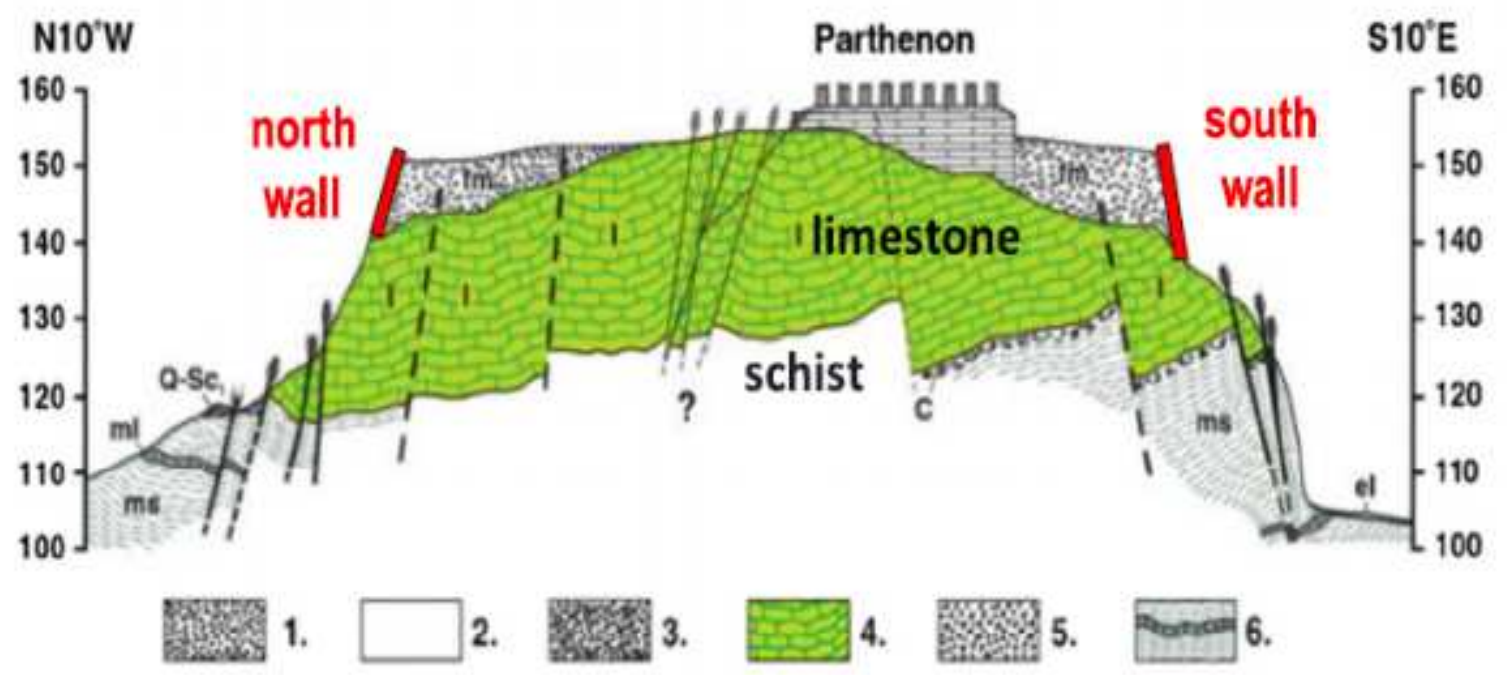

\section{Figure 2}

The prevailing geological conditions on the hill of Acropolis: 1. Artificial earthfill. 2. Eluvial mantle. 3. Talus. 4. Limestone. 5. Conglomerates. 6. Schist- Sandstone - marl series (adopted from Koukis et al. 2015). 


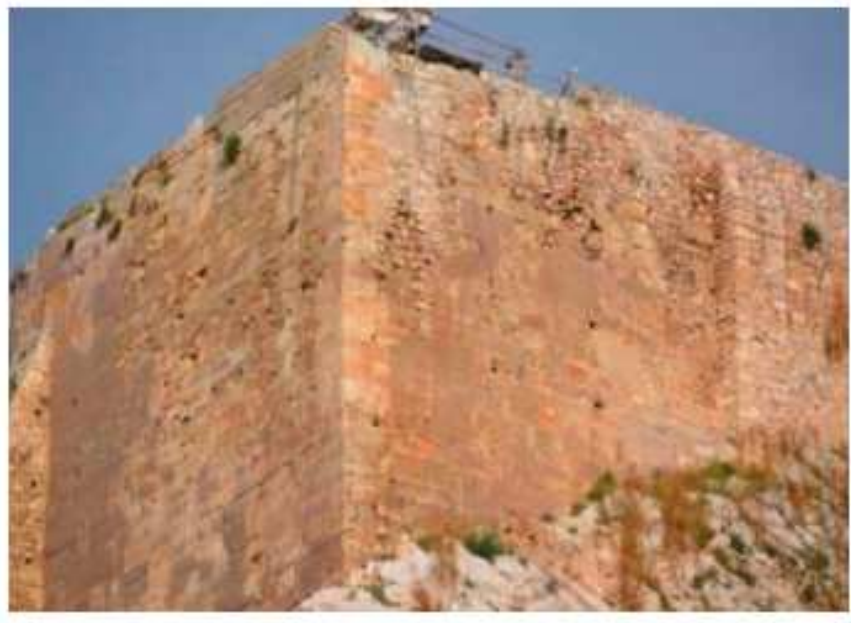

(a)

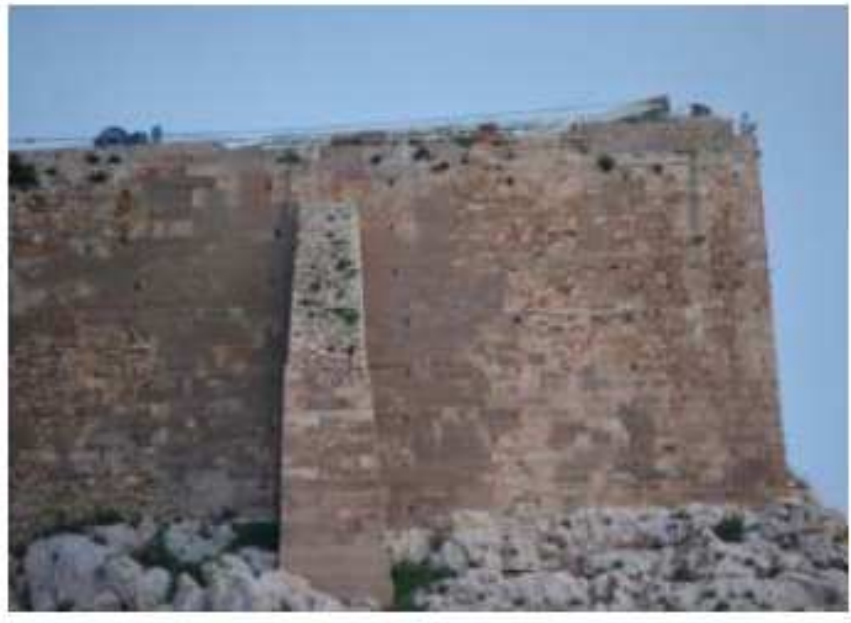

(b)

\section{Figure 3}

Cracks at the southeast corner of the Wall: (a) view from the east, (b) view from the south.

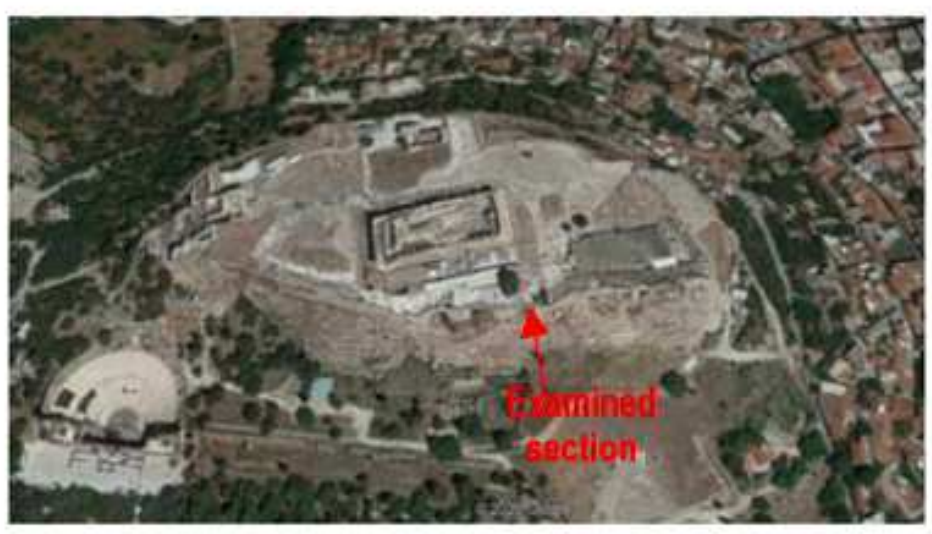

(a)

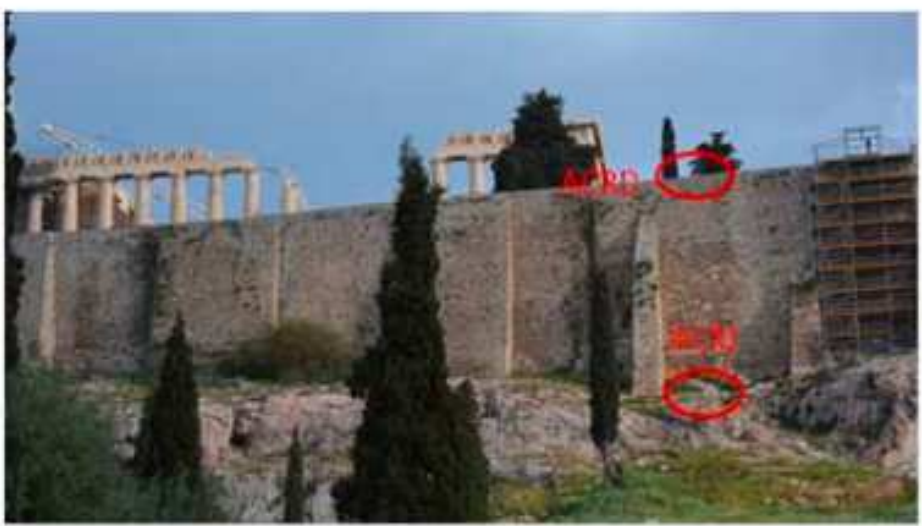

(b)

Figure 4

(a) Location of the examined section at the south part of Acropolis hill, and (b) installed accelerographs at the base (ACRJ) and at the top (ACRD) of the Wall. 


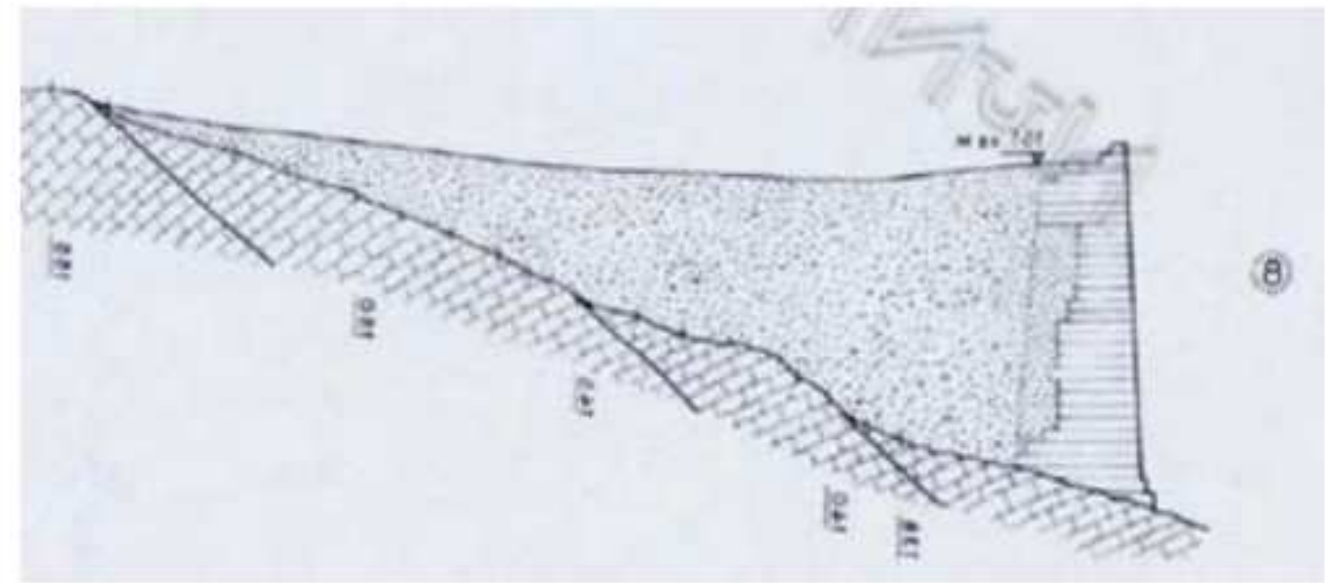

(a)

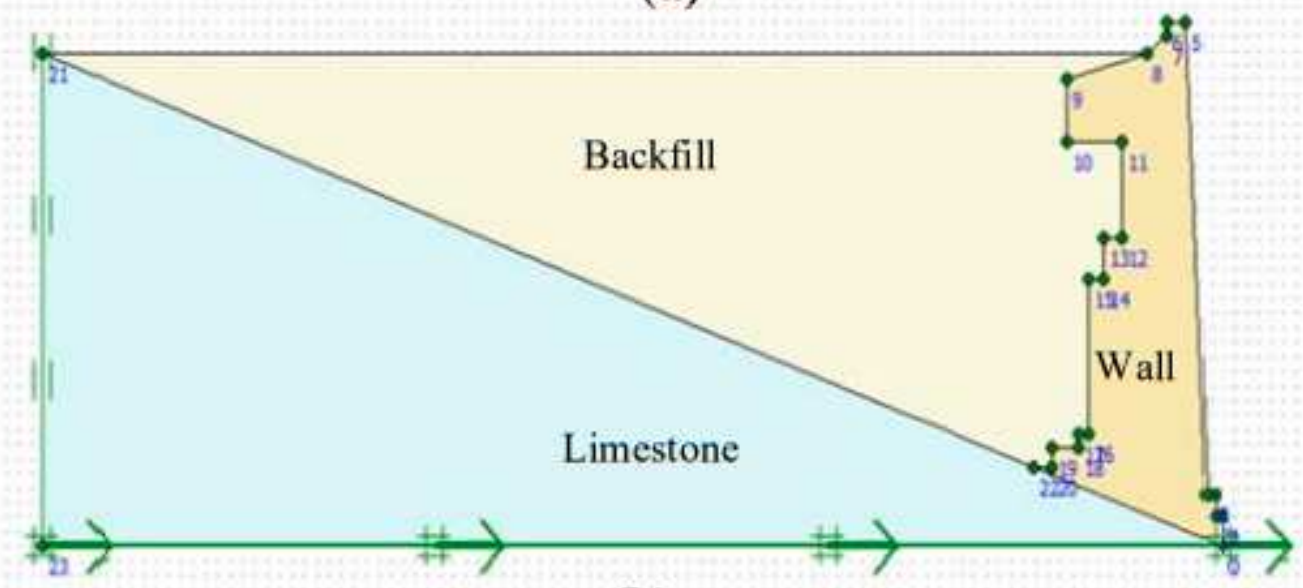

(b)

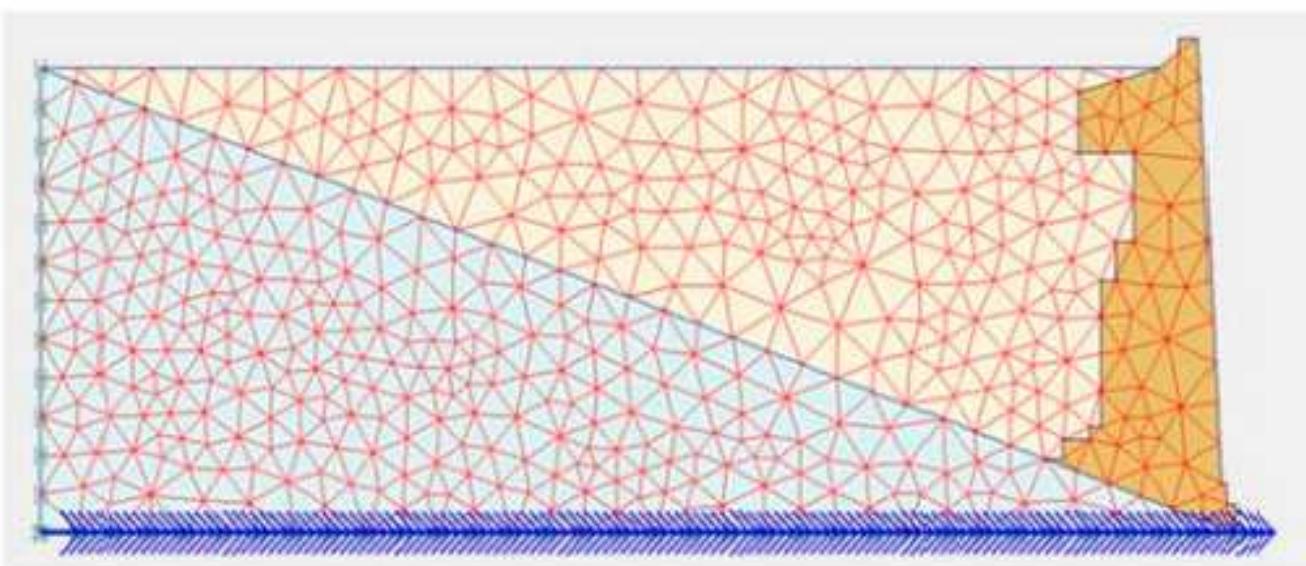

(c)

Figure 5

(a) Cross section of the examined south Wall section (adopted from Trikkalinos 1977), (b) twodimensional numerical model, and (c) finite-element discretization 


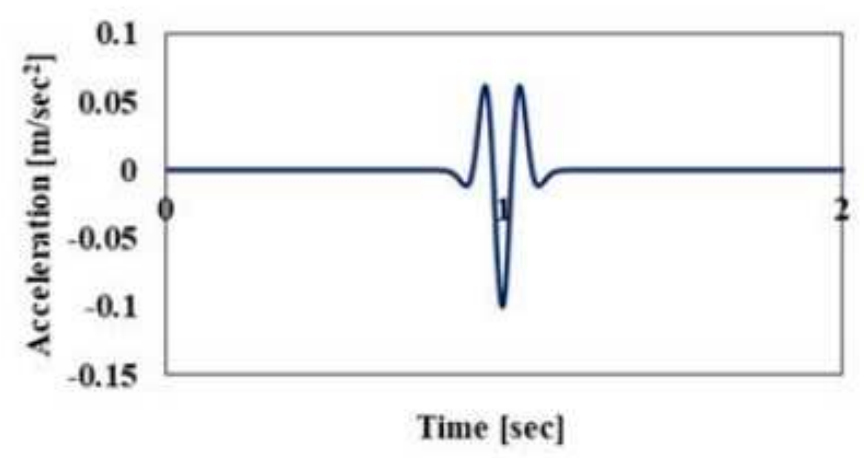

(a)

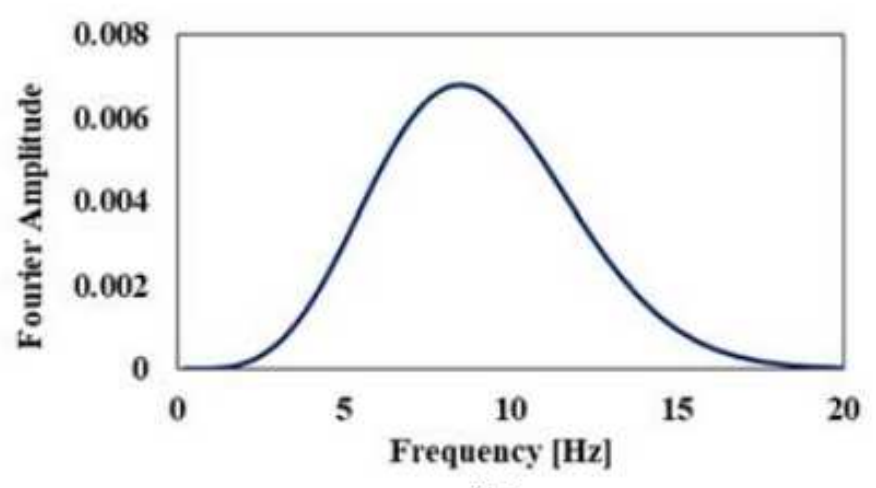

(b)

Figure 6

(a) Acceleration time history, and (b) Fourier spectrum of the Ricker $6 \mathrm{~Hz}$ pulse excitation.

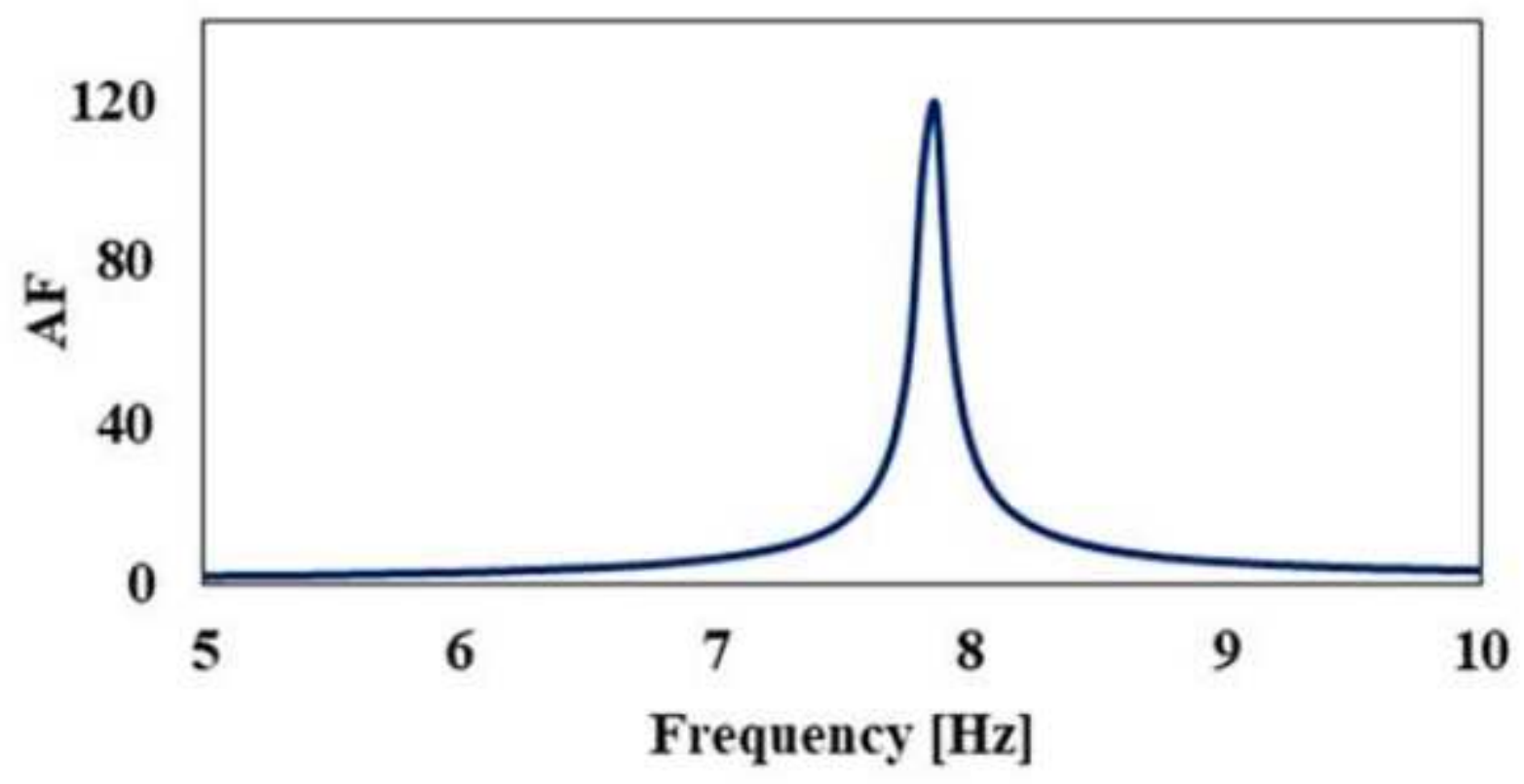

Figure 7

Acceleration Amplification Factor (AF) for the examined section of the south Circuit Wall for the Ricker 6 $\mathrm{Hz}$ excitation. 


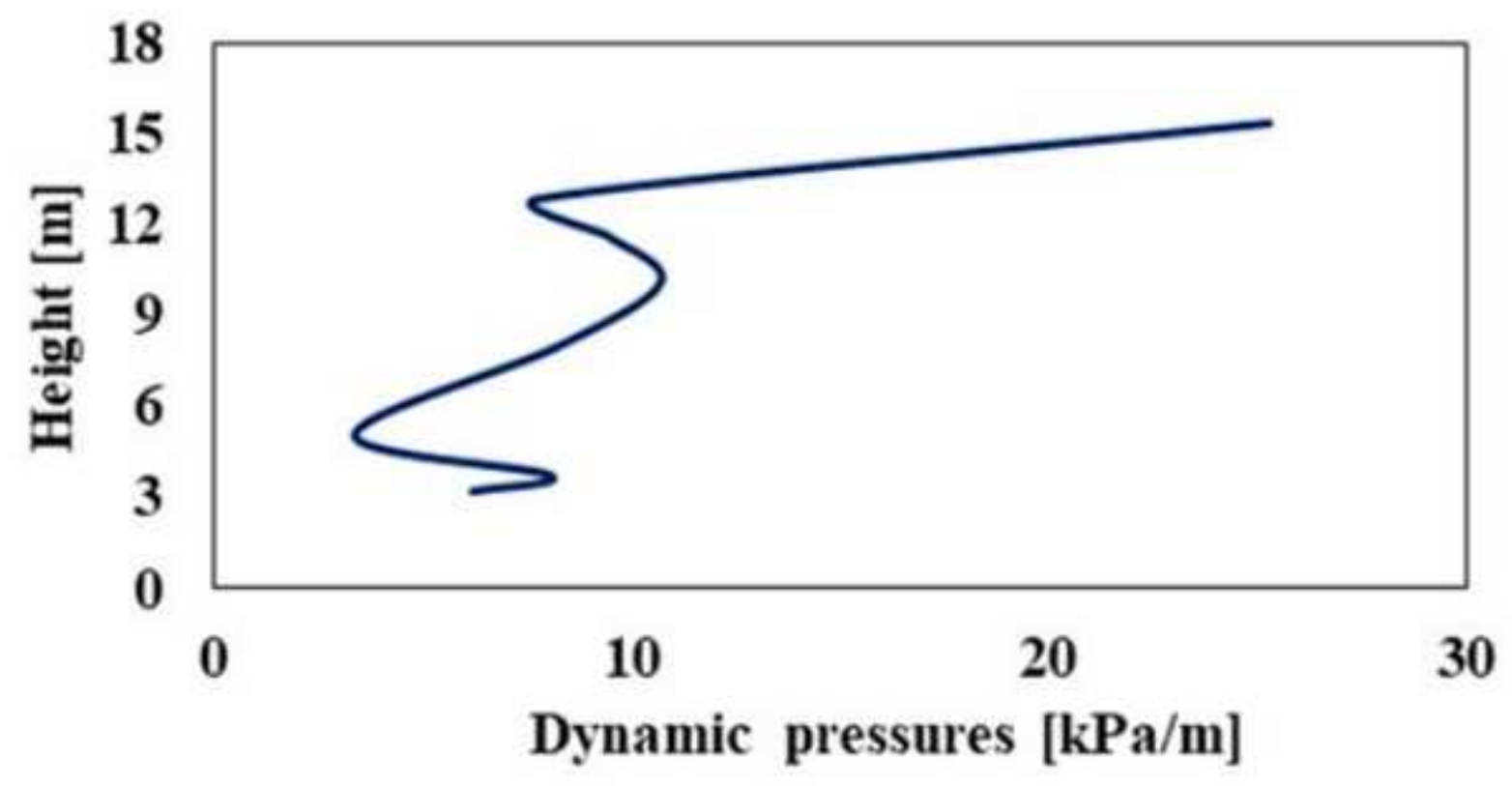

Figure 8

Height-wise distribution of the dynamic pressures on the examined section of the south Circuit Wall for the Ricker excitation.

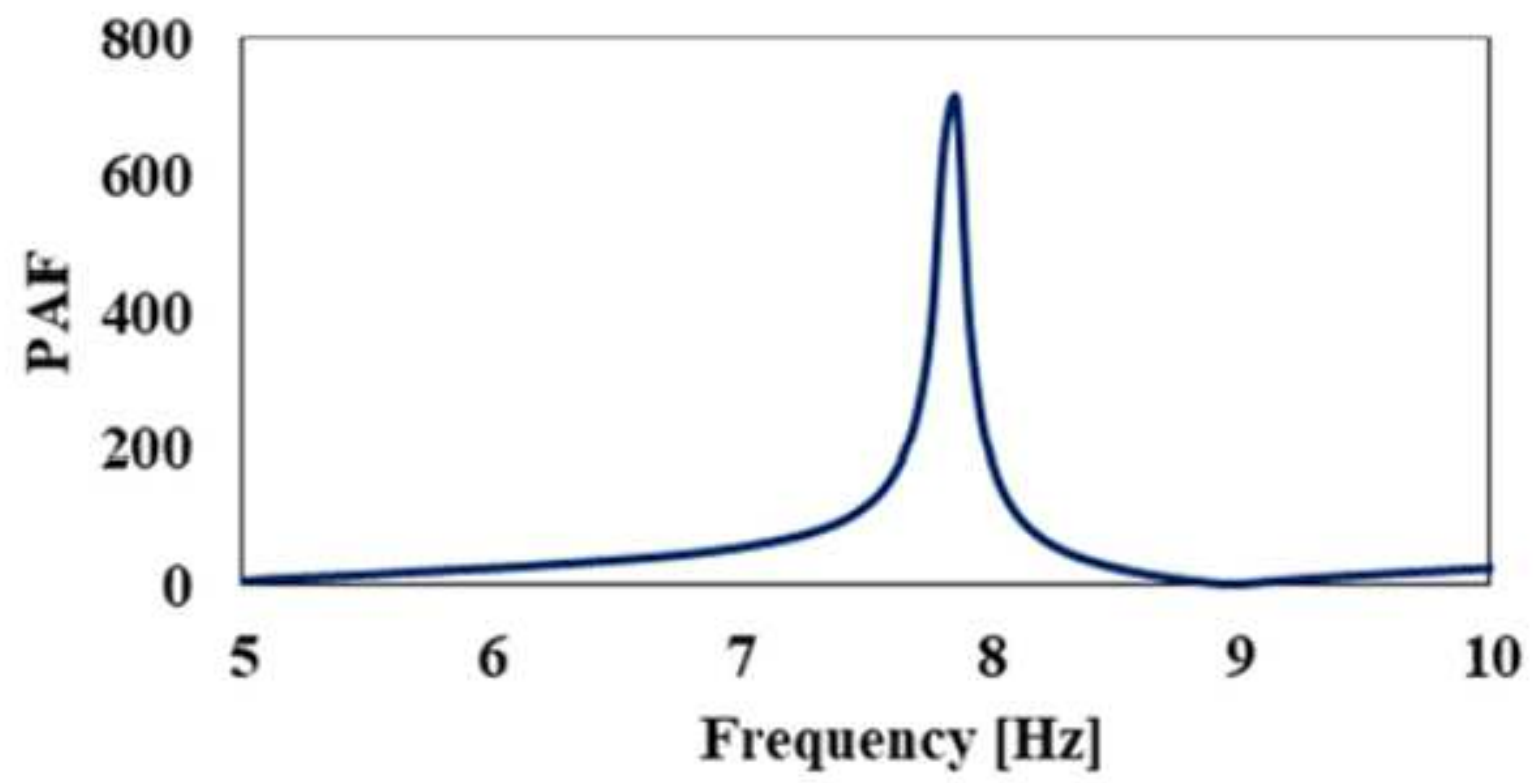

Figure 9

Pressure Amplification Factor (PAF) in the frequency domain for the south Circuit Wall section under Ricker pulse excitation. 


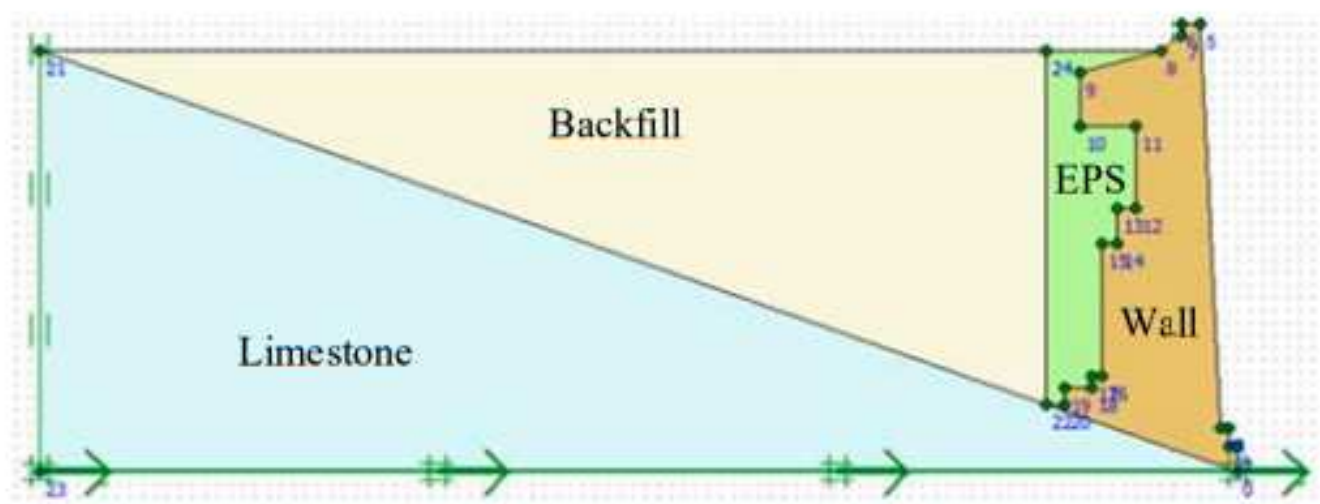

(a)

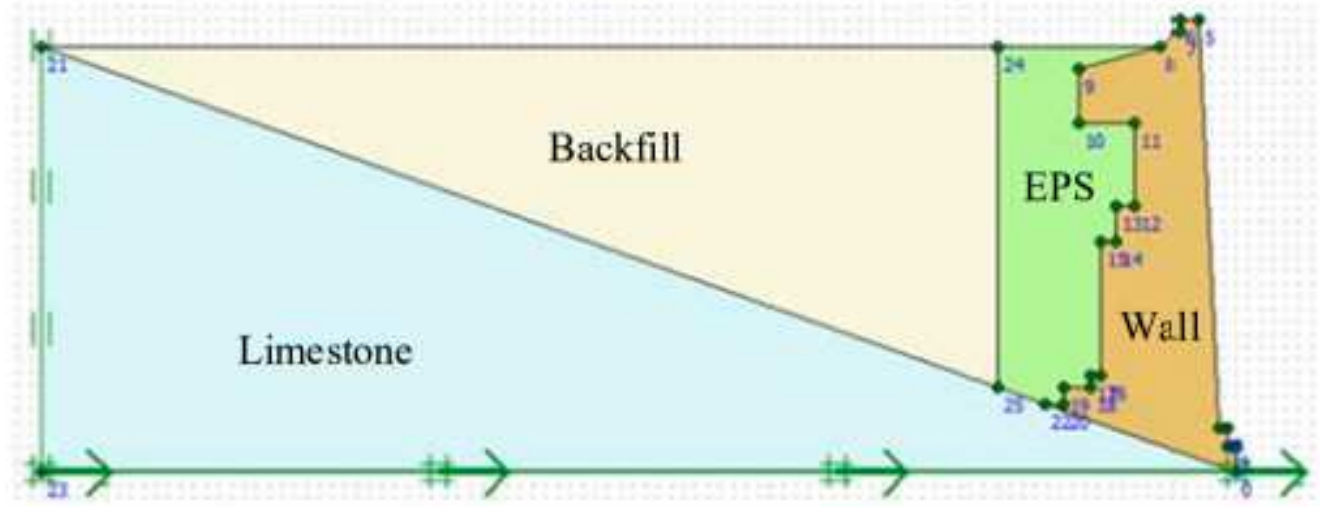

(b)

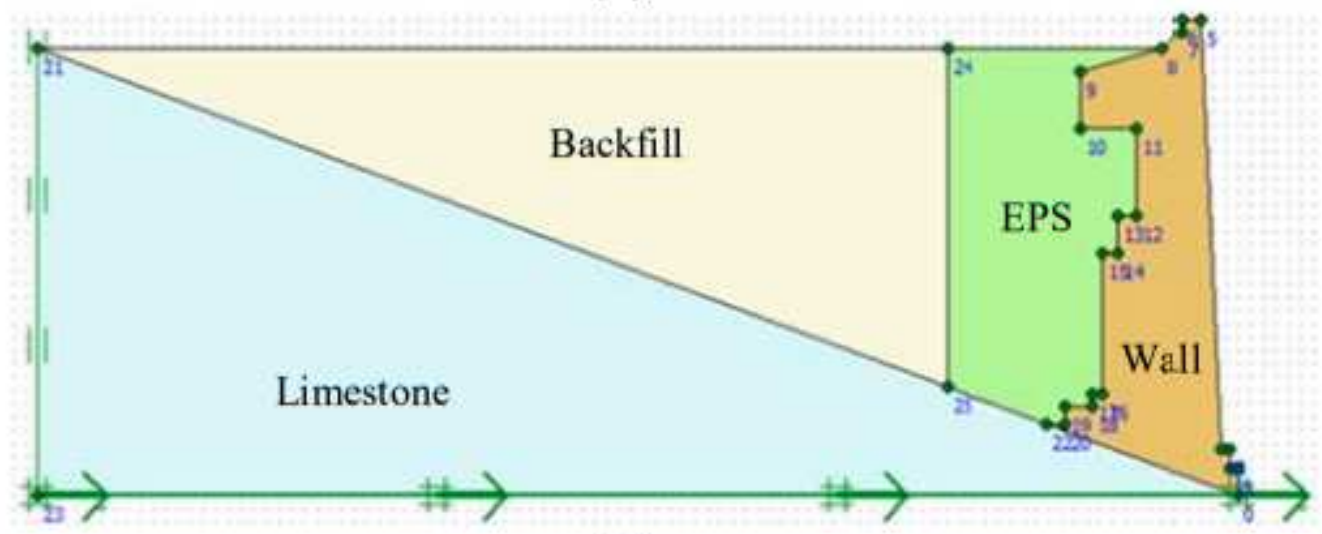

(c)

Figure 10

South Circuit Wall section with EPS inclusion along its height with average thickness: (a) $2.4 \mathrm{~m}$, (b) $4.3 \mathrm{~m}$, (c) $6.3 \mathrm{~m}$. 


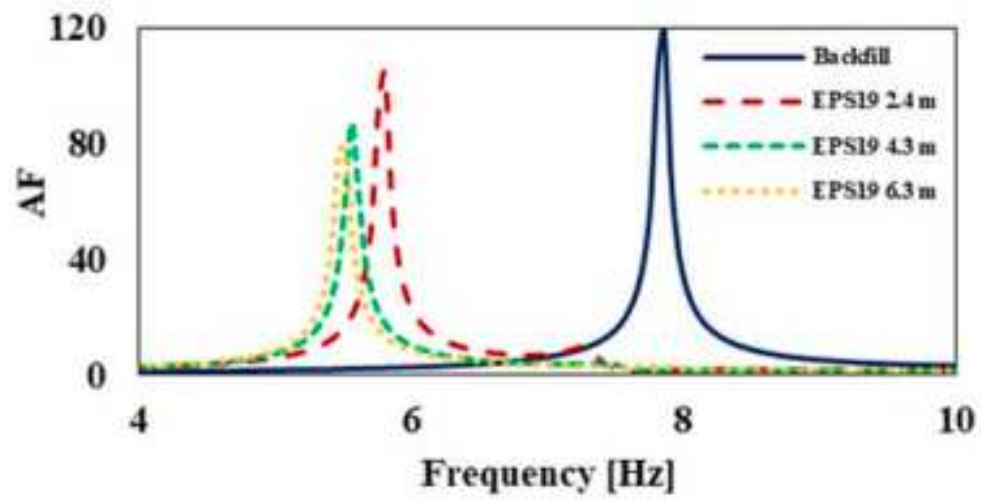

(a)

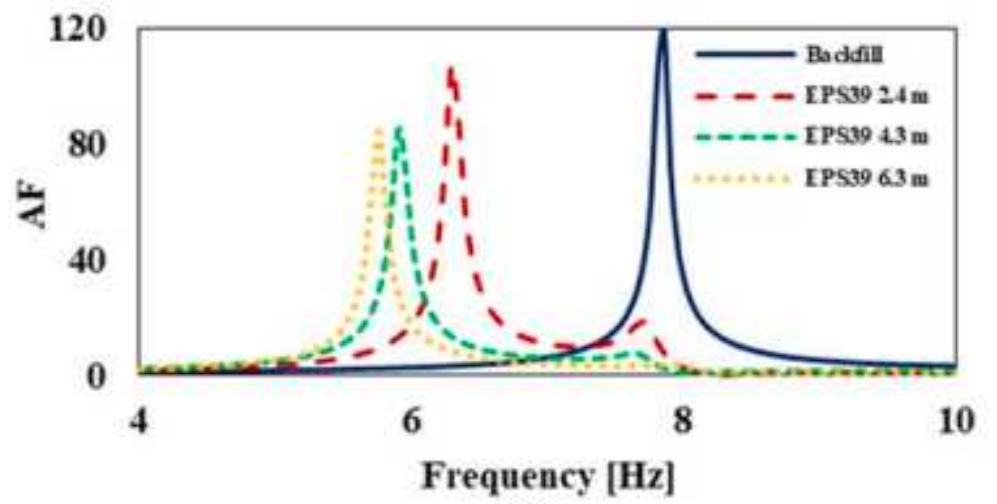

(b)

Figure 11

Amplification Factors (AF) of the examined south Circuit Wall section with: (a) EPS19 and (b) EPS39. 


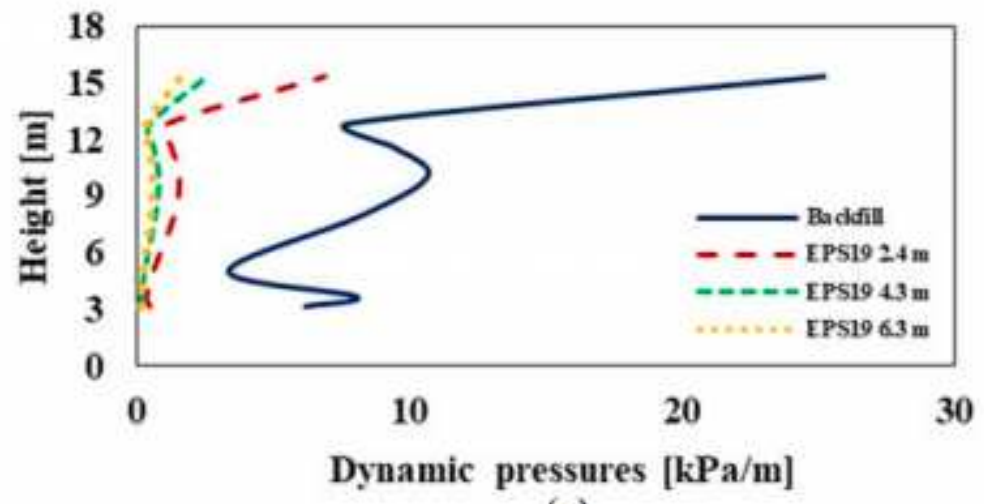

(a)

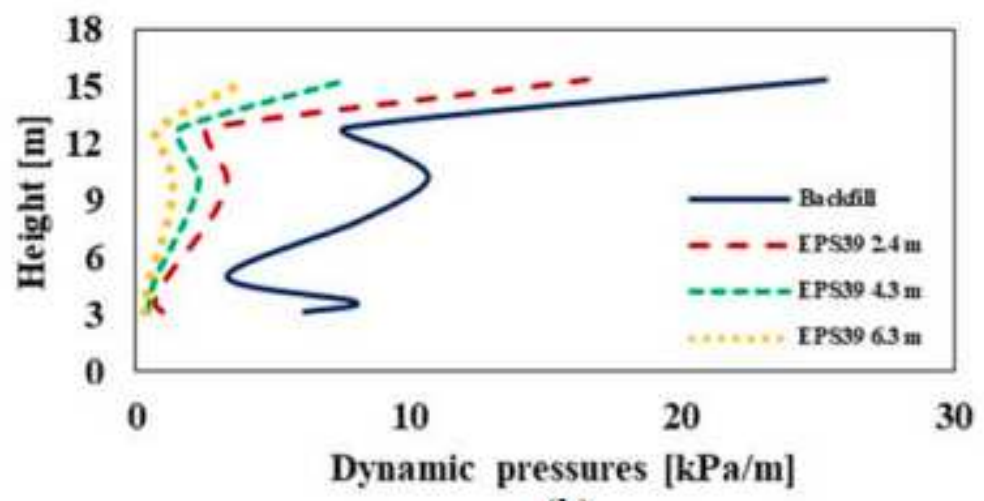

(b)

Figure 12

Height-wise distribution of the dynamic pressures for: (a) EPS19 and (b) EPS39. 


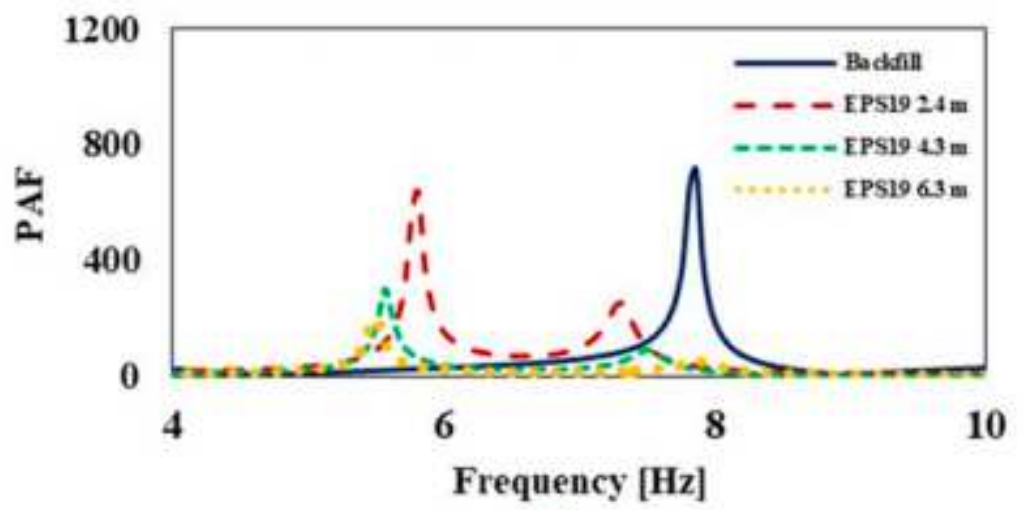

(a)

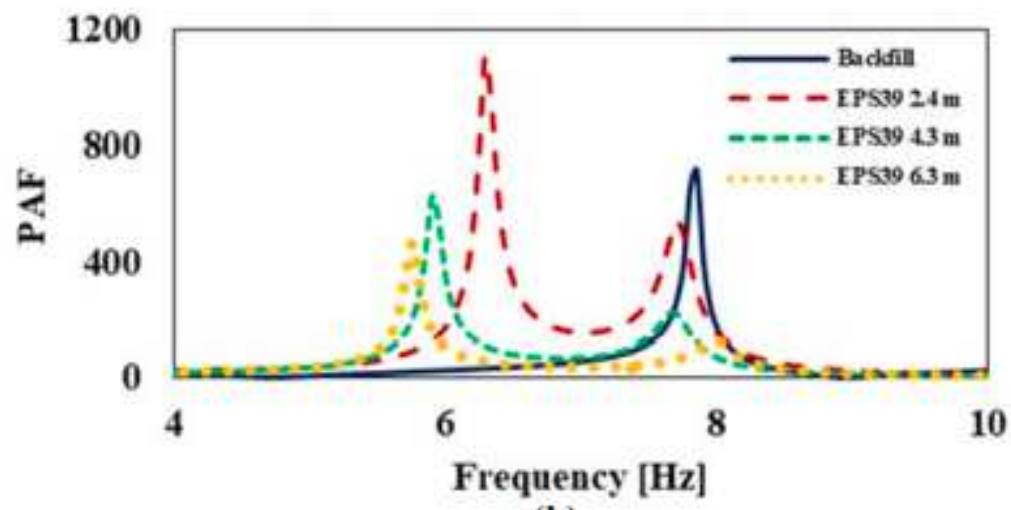

(b)

Figure 13

Pressure Amplification Factors (PAF) for: (a) EPS19 and (b) EPS39. 


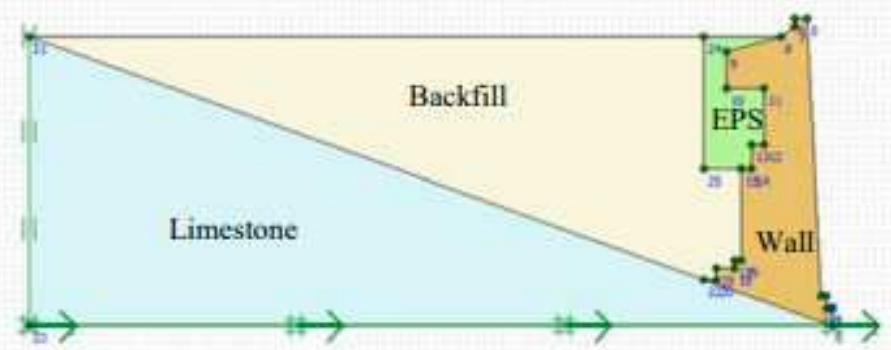

(a)

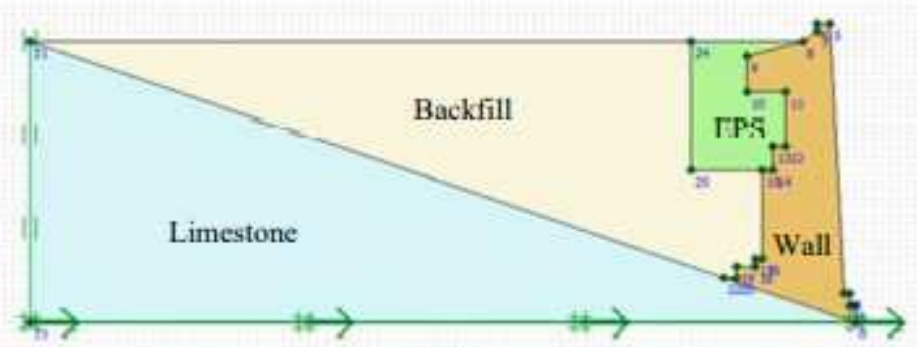

(b)

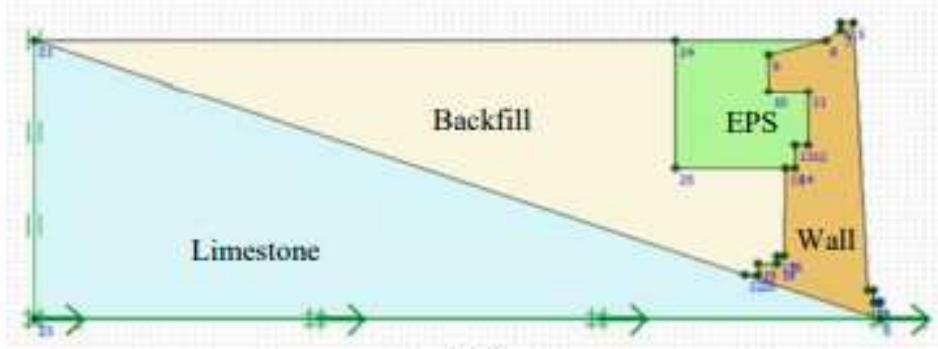

(c)

\section{Figure 14}

South Circuit Wall section with EPS at its upper part and average thickness: (a) $2.4 \mathrm{~m}$, (b) $4.3 \mathrm{~m}$, (c) $6.3 \mathrm{~m}$.

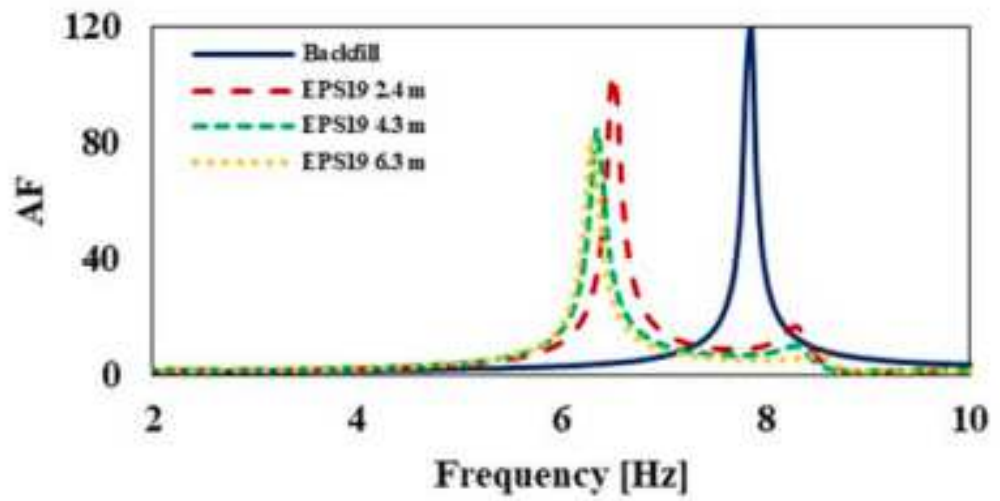

Figure 15 
Amplification Factors (AF) of the examined south Circuit Wall section mitigated at its upper part with EPS19.

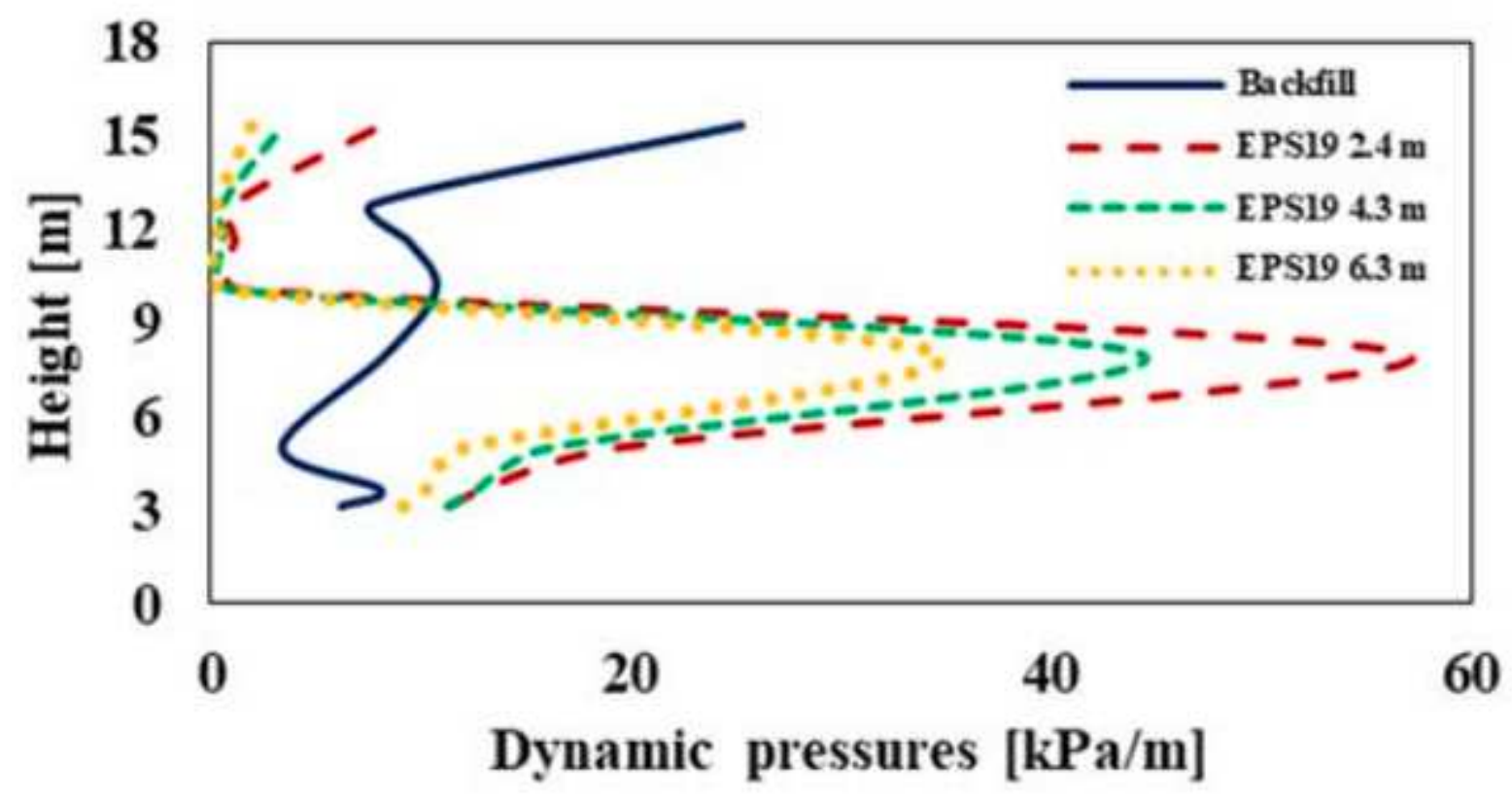

Figure 16

Height-wise distribution of the dynamic pressures for EPS19 inclusion at the upper part of the south Circuit Wall section.

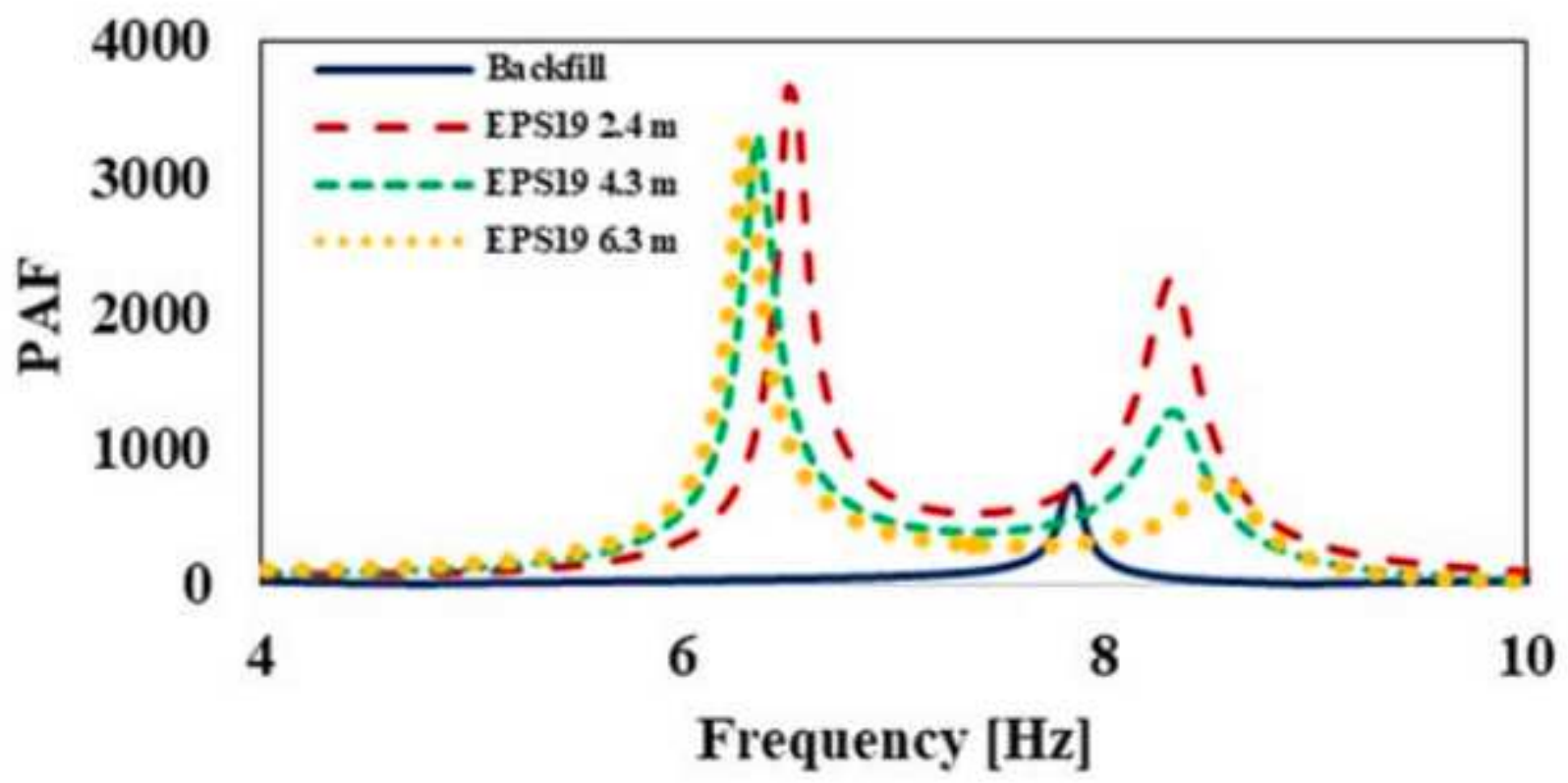

Figure 17 
Pressure Amplification Factors (PAF) of the examined south Circuit Wall section mitigated with EPS19 at its upper part.

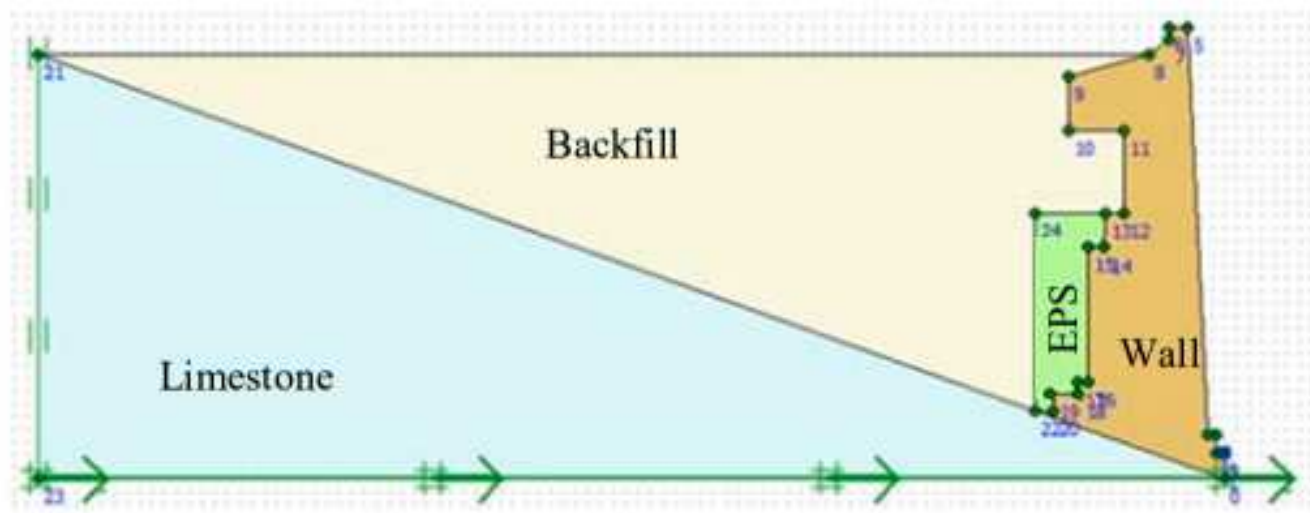

(a)

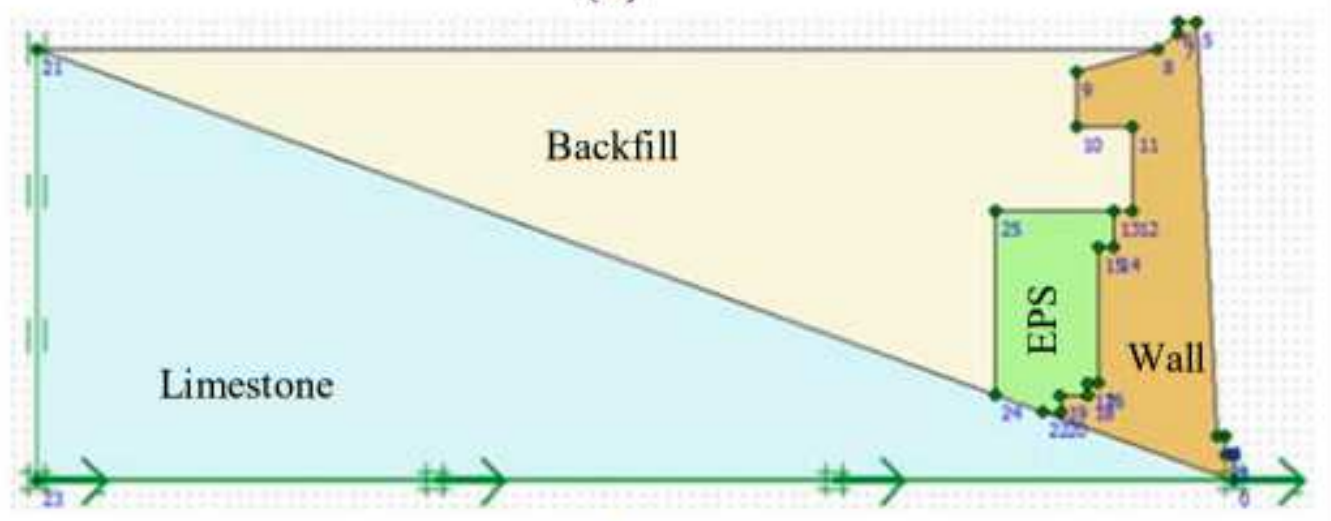

(b)

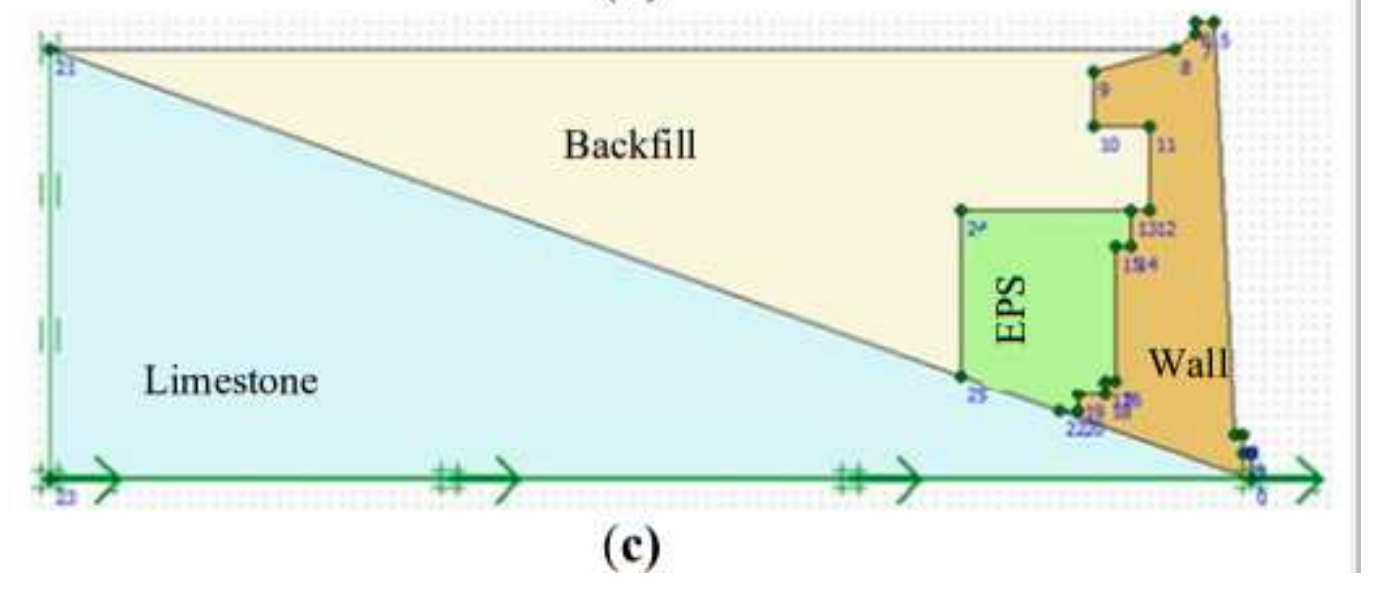

\section{Figure 18}

South Circuit Wall section with EPS at its lower part and average thickness: (a) $2.4 \mathrm{~m}$, (b) $4.3 \mathrm{~m}$, (c) $6.3 \mathrm{~m}$. 


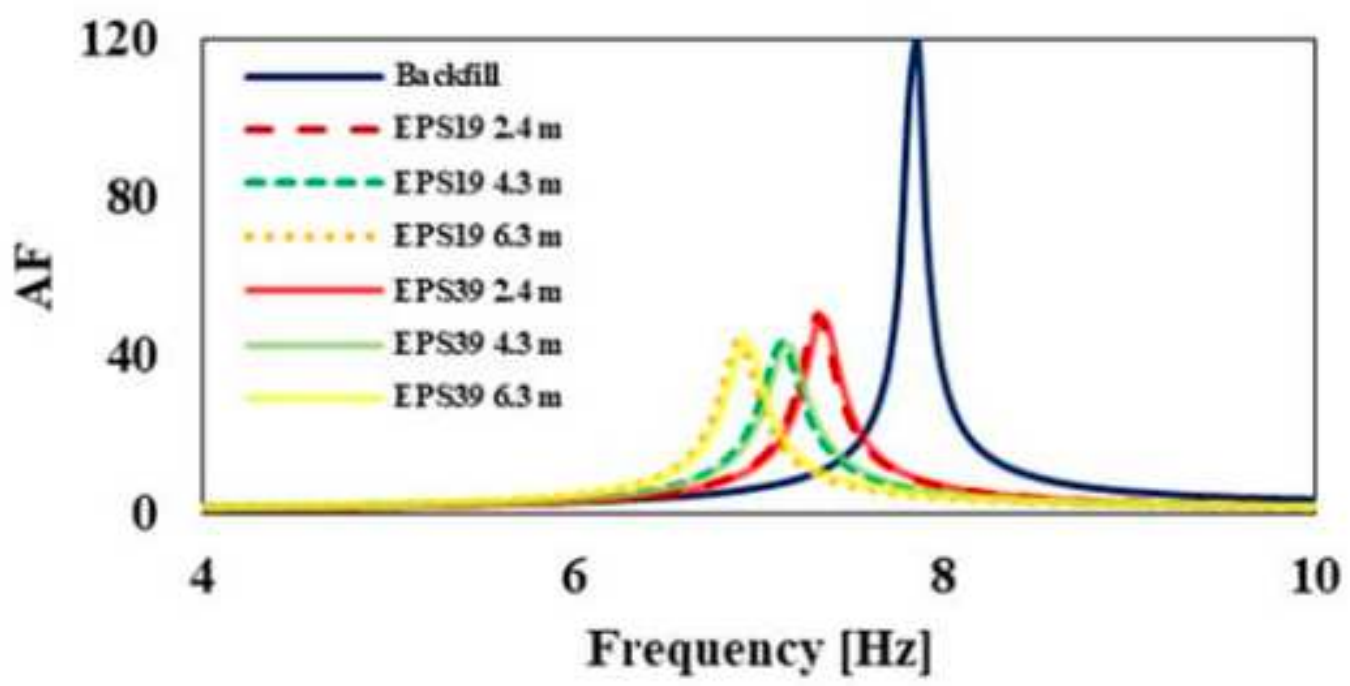

Figure 19

Amplification Factors (AF) of the examined south Circuit Wall section mitigated at its lower part.

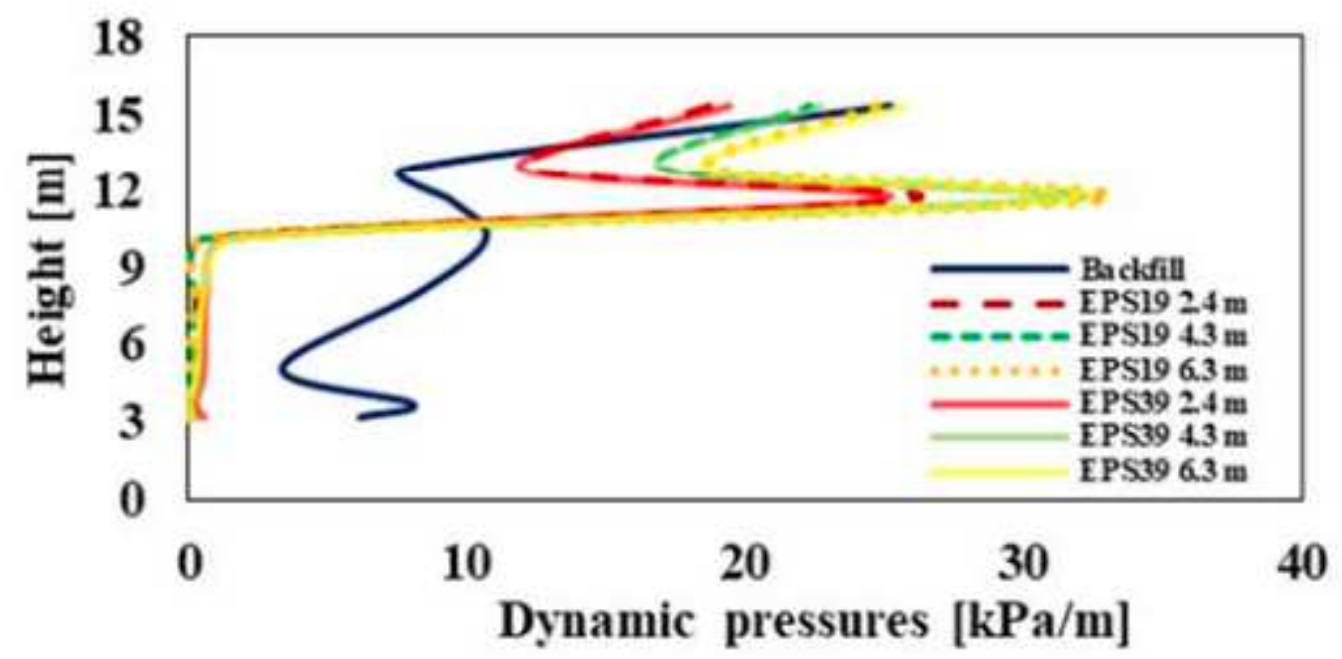

Figure 20

Height-wise distribution of the dynamic pressures with EPS at the lower part of the south Circuit Wall section. 


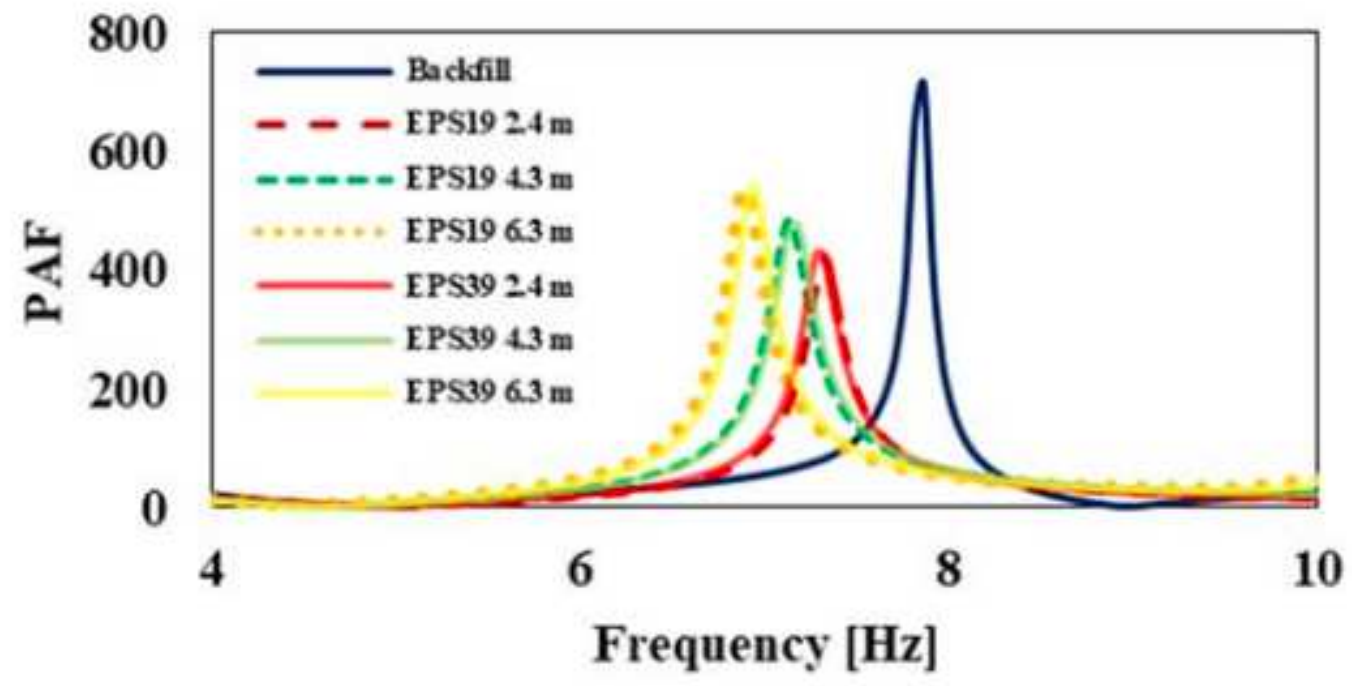

Figure 21

Pressure Amplification Factors (PAF) of the examined south Circuit Wall section mitigated with EPS at its lower part. 